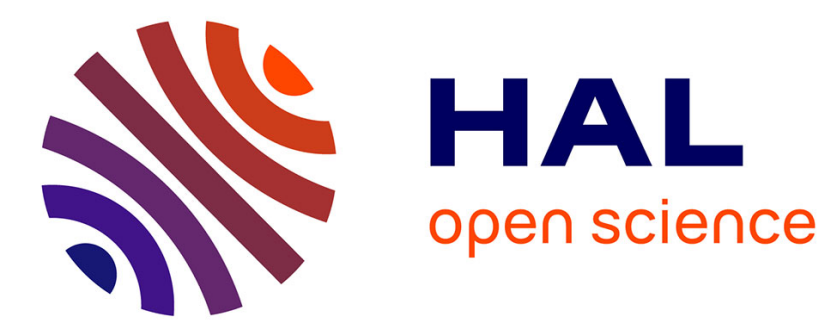

\title{
Natural convection and wall condensation or evaporation in humid air filled cavities subjected to wall temperature variations
}

H. Sun, Guy Lauriat, Xavier Nicolas

\section{- To cite this version:}

H. Sun, Guy Lauriat, Xavier Nicolas. Natural convection and wall condensation or evaporation in humid air filled cavities subjected to wall temperature variations. International Journal of Thermal Sciences, 2011, 50 (5), pp.663-679. 10.1016/j.ijthermalsci.2010.12.010 . hal-00692392

\section{HAL Id: hal-00692392 \\ https://hal.science/hal-00692392}

Submitted on 2 May 2012

HAL is a multi-disciplinary open access archive for the deposit and dissemination of scientific research documents, whether they are published or not. The documents may come from teaching and research institutions in France or abroad, or from public or private research centers.
L'archive ouverte pluridisciplinaire HAL, est destinée au dépôt et à la diffusion de documents scientifiques de niveau recherche, publiés ou non, émanant des établissements d'enseignement et de recherche français ou étrangers, des laboratoires publics ou privés. 


\title{
Natural convection and wall condensation or evaporation in humid air-filled cavities subjected to wall temperature variations.
}

\author{
H. Sun, ${ }^{*}$ G. Lauriat, ${ }^{\dagger}$ and X. Nicolas ${ }^{\ddagger}$ \\ Université Paris-Est, Marne-la-Vallée, \\ Laboratoire Modélisation et Simulation Multi Echelle \\ (MSME UMR 8208 CNRS ), 5 Bvd Descartes, \\ Champs-sur-Marne, F-77454 Marne-la-Vallée cedex 2, France
}

(Dated: December 14, 2010)

\begin{abstract}
Abstract: Heat and mass transfer by natural convection coupled to wall surface condensation or evaporation in a two-dimensional cavity subjected to uniform, but time-dependent wall temperatures is investigated numerically. At initial state, the cavity is filled with quiescent humid air at uniform temperature and density. By decreasing the wall temperature, condensation occurs at the four wall surfaces until an equilibrium thermodynamic state is reached. The walls are then heated and evaporation of the liquid water film is considered. Various time-variations of the wall temperature were investigated. Since the mass of humid air and average pressure experience large changes during transient regimes, a weakly compressible formulation has been used. The model considers only condensation/evaporation under the thin film approximation. The computations were carried out for temperatures of humid air varying between $300 \mathrm{~K}$ and $350 \mathrm{~K}$, and pressure variations around atmospheric pressure. The typical width of the cavities is $L=0.1 \mathrm{~m}$. The results show that very different transient flow structures occur during condensation and evaporation processes. The thickness distributions of the water films condensed at the walls are discussed, and it is shown that the thicknesses reflect the flow structures. The effect of the cavity aspect ratio reveals more complicated results than for convection without phase change at the wall surfaces.
\end{abstract}

Keywords Thermosolutal convection, humid air, surface condensation/evaporation, cavity flows, numerical simulations

$\dagger$ corresponding author : lauriat@univ-mlv.fr 


\section{Nomenclature}

a

A

$C_{p}$

$D_{a v}$

Fr

$g$

$h$

$h_{l v}$

H

$H_{g}$

$\overline{\bar{I}}$

J

$k$

L

Le

m

$\dot{m}$

M

$M^{*}$

n

thermal diffusivity $\left[m^{2} s^{-1}\right]$

aspect ratio, $A=H / L$

specific heat $\left[J \mathrm{~K}^{-1} \mathrm{~kg}^{-1}\right]$

binary mass diffusion coefficient $\left[m^{2} s^{-1}\right]$

Froude number, $\mathrm{Fr}=a_{0}^{2} / g L^{3}$

gravitational acceleration $\left[m s^{-2}\right]$

enthalpy $\left[J \mathrm{~kg}^{-1}\right]$

phase change enthalpy $\left[J \mathrm{~kg}^{-1}\right]$

cavity height $[m]$

dimensionless latent heat, $H_{g}=h_{l v} / C_{p 0} \Delta T$

unit tensor

mass flux density $\left[\mathrm{kg} \mathrm{m}^{-2} \mathrm{~s}^{-1}\right]$

thermal conductivity $\left[W m^{-1} K^{-1}\right]$

cavity width $[m]$

Lewis number, $L e=a_{0} / D_{a v, 0}$

mixture mass $[k g]$

mass flow rate $\left[k g s^{-1}\right]$

molecular weight $[\mathrm{kg} / \mathrm{kmol}]$

molecular weight ratio, $M^{*}=M_{v} / M_{a}$

unit inward normal to surface $d S$

$N=R a_{m} / R a_{T}$ buoyancy ratio

$\mathrm{Nu} \quad$ local Nusselt number (Eq. 32)

$N_{x}, N_{y} \quad$ numbers of grid points in $x$ - and $y$-directions

$p^{\prime} \quad$ fluctuating part of the static pressure $[\mathrm{Pa}]$

$\bar{P} \quad$ thermodynamic pressure $[P a]$

$P_{v, \text { sat }} \quad$ vapor pressure at saturation $[\mathrm{Pa}]$

$\operatorname{Pr} \quad$ mixture Prandtl number, $\operatorname{Pr}=\mu_{0} / \rho_{0} a_{0}$

$R \quad$ universal gas constant, $R=8.315 \mathrm{~kJ} \mathrm{kmol}^{-1}$

RH relative humidity [\%]

$R a_{m} \quad$ solutal Rayleigh number, $R a_{m}=\rho_{0} g \beta_{m} \Delta W L^{3} / a_{0} \mu_{0}$ 


$\begin{array}{ll}R a_{T} & \text { thermal Rayleigh number, } R a_{T}=\rho_{0} g \beta_{T} \Delta T L^{3} / a_{0} \mu_{0} \\ S c & \text { Schmidt number, } S c=\mu_{0} / \rho_{0} D_{a v, 0} \\ S h & \text { local Sherwood number (Eq. 36) } \\ t & \text { time }[s] \\ T & \text { temperature }[K] \\ \mathbf{V}=(u, v) & \text { velocity vector }\left[m s^{-1}\right] \\ W & \text { mass fraction } \\ (x, y) & \text { coordinates }[m]\end{array}$

\section{Greeks}

$\beta_{m}$

$\beta_{T}$

$\Delta m_{v}$

$\Delta T$

$\Delta W$

$\epsilon_{m}$

$\epsilon_{T}$

$\gamma$

$\mu$

$\nu$

$\Omega$

$\Psi$

$\rho$

$\tau$

$\overline{\bar{\tau}}$

$\theta$

solutal coefficient of volumetric expansion

thermal coefficient of volumetric expansion, $\beta_{T}=1 / T_{0}\left[K^{-1}\right]$

variation of the water vapor mass within the cavity $[\mathrm{kg}]$

maximum wall temperature difference, $\Delta T=\left(T_{w, \max }-T_{w, \min }\right)[K]$

water vapor mass fraction difference

non-Boussinesq solutal parameter, $\epsilon_{m}=1 / M^{*}-1$

non-Boussinesq thermal parameter, $\epsilon_{T}=\Delta T / T_{0}$

specific heat ratio, $\gamma=C_{p} / C_{v}$

mixture dynamic viscosity $\left[N m^{-1} s^{-1}\right]$

mixture kinematic viscosity $\left[m^{2} s^{-1}\right]$

volume of the enclosure $\left[\mathrm{m}^{3} / \mathrm{m}\right]$

streamfunction

density $\left[\mathrm{kg} \mathrm{m}^{-3}\right]$

dimensionless time, $\tau=a_{0} t / L^{2}$

viscous stress tensor

dimensionless temperature ratio, $\theta=\left(T-T_{0}\right) / \Delta T$

\section{Subscripts}

$\begin{array}{ll}a & \text { dry air } \\ a d v & \text { advection } \\ \operatorname{diff} & \text { diffusion }\end{array}$


wall

\section{Superscripts}

$\begin{array}{ll}- & \text { average quantity } \\ * & \text { dimensionless quantity }\end{array}$

\section{INTRODUCTION}

The study of natural convection in enclosures is of great importance in a number of applications. A considerable number of theoretical, numerical and experimental studies have been thus conducted over the last forty years on natural convection in cavities of various shapes. The idealized problem of natural convection in differentially heated rectangular cavity was the most studied, including different angles of inclination, various flow regimes and temperature dependent fluid properties. Solutal or thermosultal convection was also widely investigated for uniform wall concentrations of a dilute species in a binary mixture. These works were generally concerned with steady-state situations and were based on the Boussinesq approximation. The applications relevant to these studies are, for example, convection of moist air resulting from different levels of temperature and humidity that occurs in building construction elements, such as hollow bricks, energy efficient housing in warm and humid climates, greenhouses and flat plate solar collectors. Similar situations can be found in insulated container, liquid fuel storage, refrigeration equipment, to name just a few. The problem of wall convective condensation of vapour carried by a non-condensable gas flowing through ducts, or wall evaporation of liquid into a flowing non-condensable carrier gas, was thoroughly investigated during the last past decades, especially for humid air. A large number of works were devoted to forced or mixed convection in vertical ducts, and the 
assumption of thin film thickness was most often invoked, as in Lin et al. [1]. The flow of falling liquid films over the duct walls were also considered by using boundary layer-type formulations, for laminar as well as for turbulent duct flows. The recent papers by Rao et al. $[2,3]$ give comprehensive overviews on the current state of art pertaining to this problem. Relative to the numerous published studies on thermosolutal convection in liquid filled cavities, experimental as well as numerical works combining heat and mass convective transport in binary gas mixture has received less attention. Transient natural convection in a binary mixture in square enclosures was numerically considered by Lin et al. [4]. The emphasis was put on the effects of the combined thermal and solutal buoyancy forces on temporal evolutions of the flow patterns and heat and mass transfer. Numerical results for steady-state double diffusion in cavities submitted to either augmenting or opposing temperature and concentration buoyancy forces were presented by Béghein et al. [5]. The aim of the study was to investigate the effect of a pollutant source located on the hot or cold vertical walls on the fluid motion and heat and mass transfer rates. Double-diffusive natural convection in a vertical stack of square cavities filled with moist air, with heat and mass horizontal diffusive walls, was studied numerically by Costa [6]. Natural convection in vertical cavities filled with unsaturated humid air was theoretically considered by McBain [7] who used scale analysis from the governing equations to obtain simple formulae for heat and mass transfer rates across vertical cavities.

In all of these works, the Boussinesq approximation was invoked since only dilute gas mixtures were studied. Weaver and Viskanta $[8,9]$ investigated a cavity flow problem in which interdiffusion of species, variable thermophysical properties, Soret and Dufour effects were accounted for. A rectangular enclosure in which a mass flux occurs at a hot vertical wall due to sublimation of a solid or evaporation of a liquid and condensation at the opposite cold wall was studied. The assumption of a binary mixture of ideal gases was introduced and normal velocities at the vertical walls were determined by a mass balance as in Yan et al. [10]. Laaroussi and Lauriat [11] presented a pioneer study using a transient, low-Mach number compressible formulation to model simultaneous heat and mass transfer by natural convection in cavities filled with humid air. The computations were carried out with the use of a commercially available computational package but the thicknesses of the liquid water films due to moisture condensed at the walls were not predicted and, evaporation was not considered. An experimental and numerical study of heat and moisture transfers by natural 
convection in a cavity containing on line cylinders was recently published by Laguerre et al. [12] who have also taken into account surface radiation exchanges and variable density effects in their numerical simulations.

Unsteady thermal natural convection of fluids in enclosures under periodic variation of thermal boundary conditions has attracted a significant interest for the last two decades, as shown in the review by Wang et al. [13]. The responses of the confined fluid, when the temperature or the heat flux specified at one of the vertical walls varies periodically, were of concern in most of these studies. An extension to natural convection of fluid in an inclined cavity with a sinusoidal wall temperature on one side wall and a constant temperature on the opposite side wall was reported by Kalabin et al. [14, 15]. The case of an inclined, porousfilled cavity subjected to the same boundary conditions was conducted recently by Wang et al. [13]. In these studies, the time-averaged temperature difference between the opposing side walls was zero because one vertical wall was maintained at a constant temperature $T_{0}$, while the temperature of the opposite side wall varied by a sine law with time about $T_{0}$. For these boundary conditions, it has been shown that there is a nonzero time-averaged heat flux through inclined enclosures, and that the average Nusselt number takes a maximum value for a certain angle of inclination and a certain frequency depending on the Grashof number. This phenomenon has been termed resonance. Chung et al. [16] addressed the effect of finite thickness and thermal conductivity of a vertical boundary wall subjected to externally applied periodic temperature. Their results show that the amplitude of variations in the Nusselt number has a sharp peak when the applied frequency matches the natural frequency of the basic mode of internal gravity oscillations.

The aim of the present work is at understanding of the effects of evaporation/ condensation processes of a condensable species on the transient mean flow characteristics of a binary mixture enclosed in a cavity. A straightforward application is that of a closed container filled with humid air subjected to periodic changes in the ambient temperature around the dew point temperature. For this particular application, condensation of water vapour or evaporation of liquid water films at the surfaces of a closed cavity are predicted for various evolutions of the wall temperature. We address thus transient heat transfer by laminar thermosolutal convection and condensation or evaporation at the wall surfaces of a two-dimensional, vertical enclosure filled by a non-dilute binary mixture containing a non-condensable gas. The formulation of the governing equation is close to the one used in recently published papers 
by Sun and Lauriat [18, 19] and Sun et al. [20] for thermosolutal convection in non-dilute binary mixture. The main differences may be found in the transient boundary conditions introduced in the present work in order to properly predict variations in the mass fluxes of water vapour associated with evaporation or condensation. A low-Mach number asymptotic flow model is thus employed, and variations in the mixture mass and heat fluxes associated to evaporation or condensation are predicted. To the best of the author knowledge, this work presents a much more realistic modelling of these phase change processes in comparison with what has been published in the open literature.

The paper is organized as follows. In section 2, we present the problem formulation both in dimensional form for a general cavity flow and in dimensionless form for the specific case of a rectangular cavity with the thermal and solutal boundary conditions considered in the following sections. Section 3 describes the numerical method used to solve the conservation equations and to satisfy the overall mass conservation. In section 4 , results and discussion are presented. Concluding remarks are drawn in section 5.

\section{PROBLEM FORMULATION}

At initial state, the enclosure is filled with a binary ideal gas mixture of air and water vapor at uniform temperature and concentration fields characterized by the set of thermodynamic quantities $\left(P_{0}, T_{0}, \rho_{0}, M_{0}\right)$, where $M_{0}$ is the initial molecular weight of the mixture. The mixture is thus composed of a condensable gas and a non-condensable carrier gas. In the case of humid air, water vapor condenses at the walls if the vapor-air mixture is cooled below the dew point temperature. The thin liquid film formed at the walls (filmwise condensation) consists of only water and local thermodynamic equilibrium is considered at the liquid-vapor interface. When the wall temperature is raised above the dew point temperature, evaporation occurs. Fog formation may occur if the partial pressure of the water vapor corresponding to the temperature and total pressure at a given location within the enclosure increases above the saturation vapor pressure. In the present study, it is assumed that there is no fog formation within the cavity. Since we are considering mass transfer of water vapor into air with small temperature and mass fraction differences, the species interdiffusion flux may be neglected [11]. The transient flow induced by time-dependent wall temperatures is assumed laminar. The problem formulation is 
based on the low-Mach number approximation in order to take into account the variations of mixture density and the work of pressure forces.

\subsection{General formulation}

The mass and momentum equations for an ideal gas mixture are written as follows:

$$
\begin{gathered}
\frac{\partial \rho}{\partial t}+\nabla \cdot(\rho \mathbf{V})=\mathbf{0} \\
\frac{\partial(\rho \mathbf{V})}{\partial t}+\nabla \cdot(\rho \mathbf{V} \otimes \mathbf{V})=-\nabla p^{\prime}+\nabla \cdot \overline{\bar{\tau}}+\rho \mathbf{g}
\end{gathered}
$$

where $\overline{\bar{\tau}}$ is the viscous stress tensor for a Newtonian fluid mixture written as

$$
\overline{\bar{\tau}}=\mu\left[\nabla \mathbf{V}+(\nabla \mathbf{V})^{t}-\frac{2}{3}(\nabla \cdot \mathbf{V}) \overline{\bar{I}}\right]
$$

$p^{\prime}$ is the fluctuating part of the static pressure decomposed as

$$
p=\bar{P}(t)+p^{\prime}
$$

$\bar{P}(t)$ is the volume-averaged thermodynamic pressure and $p^{\prime}<<\bar{P}$. It is assumed that

$$
\int_{\Omega} p^{\prime} d \Omega=0
$$

where $\Omega$ is the volume of the enclosure. The energy equation in terms of temperature reads

$$
\rho C_{p} \frac{D T}{D t}=\nabla \cdot(k \nabla T)+\frac{d \bar{P}}{d t}
$$

The species conservation equation written in terms of mass fraction for water vapor is:

$$
\frac{D\left(\rho W_{v}\right)}{D t}=\nabla \cdot\left(\rho D_{a v} \nabla W_{v}\right)
$$

where $W_{v}$ denotes the mass fraction of water vapor and $D_{a v}$ the mass diffusivity of water vapor into dry air. The system of conservation equations is completed by the ideal gas law used in order to determine the density field for a mixture composed of two gases with 
molecular weights $M_{a}$ and $M_{v}$ :

$$
\rho=\frac{\bar{P}}{R T}\left(\frac{M_{a} M_{v}}{W_{v} M_{a}+W_{a} M_{v}}\right)
$$

where $\rho=\rho_{v}+\rho_{a}$. Since air does not condensate at the thermodynamic conditions considered, its density remains constant.

\subsubsection{Thermodynamic pressure and overall mass conservation.}

The assumption of mixture mass conservation is invoked for calculating the time variations of $\bar{P}$. The initial mixture mass within the cavity is $\rho_{0} \Omega$. At time $t$ it is written as:

$$
m(t)=\int_{\Omega} \rho_{m}\left(x_{i}, t\right) d \Omega=\rho_{0} \Omega+\Delta m(t)
$$

where $\Delta m(t)$ is the mass of water vapour brings (losses) into the flow domain $\Omega$ owing to evaporation (condensation) of liquid water at the wall between times $t=0$ and $t$ :

$$
\Delta m(t)=\int_{0}^{t} \int_{S} \mathbf{J}_{w} \cdot \mathbf{n} d S d t
$$

$\mathbf{J}_{w}=\rho \mathbf{V}_{w}$ is the mass flux of water vapour leaving $d S$ (evaporation) or impinging on $d S$ (condensation). Here, $\mathbf{n}$ is the unit normal to $d S$ directed toward the inside of the cavity. Since the carrier gas is incondensable, the velocity mixture can be calculated by [1]

$$
\mathbf{V}_{w}=-\left.\frac{D_{a v}}{1-W_{v, w}} \frac{\partial W_{v}}{\partial \mathbf{n}}\right|_{w}
$$

where $W_{v, w}$ denotes the mass fraction of water vapor at the interfaces between the liquid films of water and humid air. It is worth noting that $\Delta m_{v}(t)$ tends toward zero when a thermodynamic equilibrium between water vapor and wall surfaces (dry or wet) is reached because $\mathbf{V}_{w}$ vanishes. The liquid films are assumed to be extremely thin (this asssumption, extensively used in the literature, will be justified later on). They are therefore assumed to be at the wall temperatures and the conservation equations are handled in the gas flow only. $W_{v, w}$ is calculated by invoking saturation conditions at the wall temperature $T_{w}$ and given by

$$
W_{v, w}=\frac{M_{v} P_{v, s a t}\left(T_{w}\right)}{M_{v} P_{v, s a t}\left(T_{w}\right)+M_{a}\left(P-P_{v, s a t}\left(T_{w}\right)\right)}
$$


where $P_{v, \text { sat }}$ is the vapor saturation pressure at the liquid-gas interface. By assuming that the weakly compressible approximation holds, the total pressure $P$ is considered at each instant as the mixture thermodynamic pressure, i.e. $P=\bar{P}(t)$.

From the ideal gas law, the mass of the vapour-air mixture may also be written as

$$
\left.m(t)=\int_{\Omega} \rho_{(} x_{i}, t\right) d \Omega=\int_{\Omega} \frac{M P}{R T} d \Omega=\bar{P}(t) \int_{\Omega} \frac{M}{R T} d \Omega
$$

since the thermodynamic pressure is assumed uniform within the cavity. Therefore, using Eqs. 10, 11 and 13 the evolution of the thermodynamic pressure may be written as follows:

$$
\bar{P}(t)=\frac{1}{\int_{\Omega} \frac{M}{R T} d \Omega}\left\{\rho_{0} \Omega-\left.\int_{0}^{t} \int_{S} \frac{\rho D_{a v}}{1-W_{v, w}} \frac{\partial W_{v}}{\partial \mathbf{n}}\right|_{w} \cdot \mathbf{n} d S d t\right\}
$$

\subsubsection{Boundary conditions}

An initially dry elementary surface $d S$ at a temperature higher than the dew point temperature corresponding to the partial pressure of water vapor near the wall keeps dry $\left(\mathbf{J}_{w}=0\right)$. Otherwise condensation occurs $\left(P_{v}\left(T_{w}\right)>P_{v, \text { sat }}\left(T_{w}\right)\right)$ and $\mathbf{V}_{w}$ is given by Eq. 11. For an initially wet surface at temperature $T_{w}$ such that $P_{v, \text { sat }}\left(T_{w}\right)>P_{v}\left(T_{w}\right)$, the liquid film evaporates and $\mathbf{V}_{w}$ is still given by Eq. 11. Since the binary mixture is assumed to be an ideal gas, the partial pressure of water vapour at the liquid-gas interface is written as follows:

$$
P_{v}\left(T_{w}\right)=\bar{P}\left(\frac{W_{v, w} M_{a}}{\left(1-W_{v, w}\right) M_{v}+W_{v, w} M_{a}}\right)
$$

Velocity boundary conditions: The normal velocity component is expressed by Eq. 11 for the wet parts of the walls, otherwise the impermeable condition is used (i.e. $\mathbf{V}_{w} \cdot \mathbf{n}=0$ ).

Thermal boundary conditions: Owing to the thin film approximation, the continuity of temperature at the liquid film-gas interface applies as the continuity of wall to gas temperatures, i.e. $\left.T\right|_{w}=T_{w}(t), \forall t$.

Mass boundary conditions: At the dry parts of the walls, the mass flux is zero. Therefore

$$
\left.\frac{\partial W_{v}}{\partial \mathbf{n}}\right|_{w}=0
$$


otherwise, Equation 12 applies.

\subsection{Dimensionless equations for a $2 \mathrm{D}$ rectangular cavity}

A sketch of the geometry considered is shown in Fig.1. The governing equations were cast in dimensionless form by using the following dimensionless variables

$$
\begin{gathered}
x^{*}=\frac{x}{L} \quad y^{*}=\frac{y}{L} \quad \tau=\frac{t a_{0}}{L^{2}} \quad \rho^{*}=\frac{\rho}{\rho_{0}} \quad p^{*}=\frac{p^{\prime}}{\rho_{0}\left(a_{0} / L\right)^{2}} \quad \bar{P}^{*}=\frac{\bar{P}}{\bar{P}_{0}} \\
u^{*}=\frac{u}{a_{0} / L} \quad v^{*}=\frac{v}{a_{0} / L} \quad \theta=\frac{T-T_{0}}{\Delta T} \quad m^{*}=\frac{m}{\rho_{0} \Omega} \\
\mu^{*}=\frac{\mu}{\mu_{0}} \quad C_{p}^{*}=\frac{C_{p}}{C_{p_{0}}} \quad k^{*}=\frac{k}{k_{0}} \quad D_{a v}^{*}=\frac{D_{a v}}{D_{a v_{0}}} \quad M^{*}=\frac{M_{v}}{M_{a}}
\end{gathered}
$$

Subscript "0" stands for a well defined initial thermodynamic state and $\Delta T$ is the maximum wall temperature difference. The thermophysical properties used for dry air and water vapour together with the expressions applied for the mixture properties are given in the Appendix section.

The resulting dimensionless conservation equations are:

$$
\begin{gathered}
\frac{\partial \rho^{*}}{\partial \tau}+\nabla \cdot\left(\rho^{*} \mathbf{V}^{*}\right)=0 \\
\frac{\partial\left(\rho^{*} \mathbf{V}^{*}\right)}{\partial \tau}+\nabla \cdot\left(\rho^{*} \mathbf{V}^{*} \otimes \mathbf{V}^{*}\right)=-\nabla p^{*}+\operatorname{Pr} \nabla \cdot \overline{\bar{\tau}}^{*}+\frac{1}{F r} \rho^{*} \frac{\mathbf{g}}{|\mathbf{g}|}
\end{gathered}
$$

where

$$
\begin{gathered}
\overline{\bar{\tau}}^{*}=\mu^{*}\left[\nabla \mathbf{V}^{*}+\left(\nabla \mathbf{V}^{*}\right)^{t}-\frac{2}{3}\left(\nabla \cdot \mathbf{V}^{*}\right) \overline{\bar{I}}\right] \\
\rho^{*} C_{p}^{*}\left[\frac{\partial \theta}{\partial \tau}+\mathbf{V}^{*} \nabla \theta\right]=\nabla \cdot\left(k^{*} \nabla \theta\right)+\frac{(\gamma-1)}{\gamma \epsilon_{T}} \frac{d \overline{P^{*}}}{d \tau} \\
\frac{\partial\left(\rho^{*} W_{v}\right)}{\partial \tau}+\nabla \cdot\left(\rho^{*} \mathbf{V}^{*} W_{v}\right)=\frac{1}{L e} \nabla \cdot\left(\rho^{*} D_{a v}^{*} \nabla W_{v}\right)
\end{gathered}
$$

where $\operatorname{Fr}=a_{0}^{2} / g L^{3}, \operatorname{Pr}=\mu_{0} / \rho_{0} a_{0}, L e=a_{0} / D_{a v, 0}$, are the Froude, Prandtl and Lewis 
numbers, respectively. $\gamma=C_{p} / C_{v}$ is the ratio of specific heats. $\epsilon_{T}=\Delta T / T_{0}$ characterizes the thermal deviation from the Boussinesq approximation. The dimensionless thermodynamic pressure may be written as

$$
\bar{P}^{*}(\tau)=\frac{1}{\int_{0}^{A} \int_{0}^{1}\left(\frac{1}{\epsilon_{T} \theta+1}\right)\left(\frac{\epsilon_{m} W_{v, 0}+1}{\epsilon_{m} W_{v}+1}\right) d x^{*} d y^{*}}\left\{A+\Delta m_{v}^{*}(\tau)\right\}
$$

In the above expression, $A=H / L$ is the cavity aspect ratio and $\epsilon_{m}$ characterizes the solutal deviation from the usual assumption of binary dilute solutions. It reads

$$
\epsilon_{m}=\frac{1}{M^{*}}-1
$$

The term $\Delta m_{v}^{*}(\tau)$ denotes the change in mass of water vapor inside the cavity due to evaporation or condensation at the walls between the initial state and time $\tau$. It is given by:

$$
\Delta m_{v}^{*}(\tau)=\int_{0}^{\tau} \int_{S} \rho^{*} \mathbf{V}_{w}^{*} \cdot \mathbf{n} d S d \tau
$$

The local dimensionless mixture density is obtained from the ideal gas law as follows:

$$
\rho^{*}=\frac{\bar{P}^{*}(\tau)\left(1+\epsilon_{m} W_{v, 0}\right)}{\left(1+\epsilon_{T} \theta\right)\left(1+\epsilon_{m} W_{v}\right)}
$$

\subsubsection{Initial and boundary conditions}

The initial values of the dimensionless variables are:

$\mathbf{V}^{*}=0, \theta=0, W_{v}=W_{v, 0}, \rho^{*}=1, \bar{P}^{*}=1$ at $\tau=0 \quad \forall\left(x^{*}, y^{*}\right) \in[0,1] \times[0, A]$

At the liquid-vapor interfaces along the wet parts of the walls at temperature $T_{w}$, the vapor mass fraction is obtained from:

$$
W_{v, w}\left(\theta_{w}\right)=\frac{M^{*} P_{v, s a t}^{*}\left(\theta_{w}\right)}{P_{v, s a t}^{*}\left(\theta_{w}\right)\left(M^{*}-1\right)+\bar{P}^{*}}
$$

For $\tau>0$, the dimensionless boundary conditions at surface $S$ having an inward normal 
vector $\mathbf{n}$ and a tangential vector $\mathbf{t}$ are:

$$
\begin{gathered}
\mathbf{V}_{w}^{*} \cdot \mathbf{t}=0, \quad \mathbf{V}_{w}^{*} \cdot \mathbf{n}=-\frac{\chi D_{a v}^{*}}{\operatorname{Le}\left(1-W_{v, w}\right)} \nabla W_{v, w} \cdot \mathbf{n} \\
\theta(\tau)=\theta_{w}(\tau) \\
(1-\chi) \nabla W_{v, w} \cdot \mathbf{n}+\chi\left(W_{v}-W_{v, w}\left(\theta_{w}\right)\right)=0
\end{gathered}
$$

where $\chi=0$ at a dry point and $\chi=1$ at a wet point on the surface.

The set of 11 dimensionless parameters involved in the above problem formulation is listed below.

- Eight parameters are introduced into the dimensionless conservation and state equations:

$$
\begin{gathered}
A=H / L \quad F r=a_{0}^{2} / g L^{3} \quad \operatorname{Pr}=\nu_{0} / a_{0} \quad L e=a_{0} / D_{a v_{0}} \\
M^{*}=M_{v} / M_{a} \quad \gamma=C_{p} / C_{v} \quad \epsilon_{m}=\frac{1}{M^{*}}-1 \quad \epsilon_{T}=\Delta T / T_{0}
\end{gathered}
$$

- One parameter is introduced into the initial and boundary conditions: $W_{v, 0}=f\left(R H_{0}\right)$ where $\mathrm{RH}_{0}$ is the relative humidity at initial state.

- Two parameters characterizes the evolution of the wall temperature $\theta_{w}(\tau)$ : the amplitude and the period.

The four relationships used to calculate the thermophysical properties of humid air are given in the Appendix section.

For low temperature and mass fraction differences, the present problem formulation turns into the Boussinesq formulation [19], which can be viewed as a reference case. Most of the papers published on natural convection in cavities, thermal as well as solutal convection, were indeed based on the Boussinesq approximation. In that case, the leading flow parameters are the solutal and thermal Rayleigh numbers. For comparison purpose, it is thus relevant to introduce a dimensionless motion pressure, $p^{*}=p^{*}+y^{*} / F r$, and to re-write the buoyancy term in Eq. 18 as $-\left(R a_{T} \theta+R a_{m} W_{v}\right) \operatorname{Pr}$ or as $-R a_{T}\left(\theta+N W_{v}\right) \operatorname{Pr}$.

\subsubsection{Heat and mass fluxes at the walls}


In transient regime, the heat and mass fluxes at the walls are the sum of a diffusion term and a phase change term. This last term vanishes at dry surface locations. Here, the Nusselt numbers are defined as the ratio of the total heat flux over a reference heat flux due to heat conduction alone in the cavity, the temperature difference being the maximum temperature difference between the initial and final state or, for oscillating temperature wall, the amplitude of temperature fluctuations. The reference conduction heat flux is defined as

$$
q_{\text {ref }}=k_{0} \frac{\Delta T}{L}
$$

As a result, the local Nusselt number at a point $\mathrm{M}$ on the walls is given by:

$$
N u(M, \tau)=\left.k^{*} \nabla \theta\right|_{w} \cdot \mathbf{n}-\chi H_{g} \rho^{*}\left(\mathbf{V}_{w}^{*} \cdot \mathbf{n}\right)=N u_{d i f f}+N u_{l v}
$$

where $H_{g}=h_{l v} / C_{p_{0}} \Delta T$. For condensation of water vapor or evaporation of liquid water, $H_{g}$ is much larger than one. The surface averaged Nusselt number at wall " $i$ " of area $S_{i}$ is as follows

$$
\overline{N u}_{i}(\tau)=\frac{1}{S_{i}} \int_{S_{i}} N u(M, \tau) d S_{i}
$$

The Nusselt number averaged over the four wall of total area $\mathrm{S}$ is written as:

$$
\overline{N u}_{t}(\tau)=\frac{1}{S} \sum_{i=1,4} S_{i} \overline{N u}_{i}(\tau)
$$

The reference diffusion mass flux is defined as:

$$
q_{m, r e f}=\rho_{0} D_{a v 0} \frac{\Delta W_{v, \max }}{L}
$$

where $\Delta W_{v, \max }=W_{v, w}\left(T_{w, \max }\right)-W_{v, w}\left(T_{w, \min }\right)$ is the maximum possible difference in the mass fractions corresponding to saturation conditions at $T_{w, \max }$ and $T_{w, \min }$.

The local Sherwood number is expressed as

$$
S h(M, \tau)=\chi\left[\left.\rho^{*} D_{a v}^{*} \nabla W_{v}^{*}\right|_{w} \cdot \mathbf{n}-L e \rho^{*}\left(\mathbf{V}_{w}^{*} \cdot \mathbf{n}\right) W_{v, w}^{*}\left(\theta_{w}\right)\right]=S h_{d i f f}+S h_{a d v}
$$

where $W_{v}^{*}=W_{v} / \Delta W_{v, \max }$ The various averaged Sherwood numbers are defined as their 
Nusselt number counterpart.

\section{NUMERICAL METHOD}

The finite volume method was employed to discretize the system of conservation equations on staggered, non-uniform Cartesian grids with a second-order central difference scheme for the convective terms. The IDEAL algorithm recently proposed by Sun et al. [17] for incompressible fluid flow and heat transfer was used to solve the velocity-pressure coupling. The time integration was performed with an Alternating Direction Implicit scheme (ADI), and at each time step there existed an inner doubly iterative process to obtain the pressure field solution. A mesh study was conducted by using uniform grids having from $64 \times 64$ to $512 \times 512$ nodes. The adopted convergence criterion required that relative maximum mass and field variable residuals were less than $10^{-9}$. Detailed validation of the code for nonBoussinesq thermosolutal convection in a square cavity may be found in Sun and Lauriat $[18,19]$ and in Sun et al. [20].

The test case discussed here is for isothermal evaporation of liquid film (pure solutal convection) in a square cavity $(10 \mathrm{~cm} \times 10 \mathrm{~cm})$ initially filled with dry air at $T_{0}=350 \mathrm{~K}$ and at atmospheric pressure. The two vertical walls were assumed to be initially covered by a thin film of liquid water $\left(m_{l, 0}=1.284 \mathrm{~g} / \mathrm{m}\right.$, i.e. a uniform liquid film thickness $\left.e=6.42 \mu \mathrm{m}\right)$. The final state can be straightforwardly obtained from basic thermodynamic calculations. At steady-state, the walls are dry because all the liquid water has evaporated into air. The result is a humid air mixture with $R H=50 \%$ (relative humidity). The thermodynamic pressure and density are thus increased up to $P_{\infty}=1.22110^{5} \mathrm{~Pa}$ and $\rho_{\infty}=1.137 \mathrm{~kg} / \mathrm{m}^{3}$, respectively. This final state must be predicted numerically within a given accuracy and the mass of the mixture plus that of liquid must be constant at each instant. It should be noted here that the evaporation rate along the vertical walls is not uniform since natural convection occurs at first with a solutal Froude number $\mathrm{Fr}=8.7810^{-8}(\mathrm{Le}=0.789)$. When the mass fraction of water vapour within the cavity becomes almost uniform, the mass transfer turns into a diffusive regime. The computations showed that the final state was reached within maximum relative discrepancies less than $0.03 \%$ both for pressure and density, whatever the grid resolution in the range $[64 \times 64,512 \times 512]$. From Fig. 2 a showing the evolution of the average mixture density for various grid resolutions, it can be concluded that natural 
convection turns into diffusion after about $20 \mathrm{~s}$ while density increases sharply during the first $5 \mathrm{~s}$. The evolution of the mean Sherwood numbers at the vertical walls during the evaporation period (Fig. 2b) shows that a coarse mesh leads to a non-monotonous decrease in the mean Sherwood number when parts of the walls become dry. This behaviour is due to sudden changes in the boundary conditions for velocity and mass fraction (refer to Eqs. 28 and 30). For too large mesh sizes, these local changes lead to a series of minimum followed by maximum values in $\overline{S h}$. The zoom in Fig. $2 \mathrm{~b}$ shows that a uniform $256 \times 256$ grid may be considered as a good compromise between accuracy and computational costs.

\section{RESULTS AND DISCUSSION}

A first series of computations was conducted for a square cavity $(A=1)$ of $10 \mathrm{~cm}$ width initially filled with dry or humid air at atmospheric pressure and uniform temperature. Before considering periodic variations of the wall temperature, the simplest cases of linear variations of the wall temperature were studied. It is shown that the mathematical model allows to properly predict the evolutions of the gas mixture properties from an initial state up to a well defined steady-state. However, these computations clearly display that too sharp increases or decreases in the wall temperature may lead to local supersaturations which are admissible provided they do not exceed the critical supersaturation corresponding to the local temperature within the cavity [21-23]. If excessive local supersaturations are achieved, onset of fog formation due to homogeneous nucleation within the fluid phase may occur. Since the problem formulation does not incorporate this phase change process, the possible occurrence of transient, high supersaturating conditions at some part in the flow field must be avoided. From a physical point of view, supersaturation takes place at point where very fast variations in temperature occur. All the computations were conducted for a maximum temperature difference $\Delta T=50 \mathrm{~K}$. The following set of parameters was kept fixed: $M^{*}=0.622, \gamma=1.4, \epsilon_{m}=0.608$. The transient local thickness of the liquid film at point $M$ on a wall was calculated from the following expression:

$$
e(M, t)=\frac{\int_{0}^{t} \rho \mathbf{V}_{w}(M) \cdot \mathbf{n}(M) d t}{\rho_{\text {water }}}
$$




\subsection{Linear variation of the wall temperature.}

The uniform wall temperatures were varied linearly from $T_{0}=300 \mathrm{~K}$ to $T_{\infty}=350 \mathrm{~K}$ for evaporation and from $T_{0}=350 \mathrm{~K}$ to $T_{\infty}=300 \mathrm{~K}$ for condensation. In both cases, the decrease (increase) in temperature was sudden $(\delta t=0 \mathrm{~s})$ or occurred during $\delta t=20 \mathrm{~s}, 60 \mathrm{~s}$ or $120 \mathrm{~s}$.

4.1.1 Evaporation. The initial conditions for the study of evaporation were for a cavity filled with saturated humid air $\left(W_{v, 0}=0.0219\right.$ or $\left.R H_{0}=100 \%\right)$ at $T_{0}=300 \mathrm{~K}$. The four walls of the cavity were wetted by a thin film of liquid water of uniform thickness $e=2.57 \mu m$ (i.e. a mass of liquid equal to $m_{l, 0}=1.03 \mathrm{~g} / \mathrm{m}$ ). Such a small liquid film thickness precludes fall of the liquid films and support the assumptions of zero tangential velocity at the liquid-gas interfaces and, negligible thermal resistance of the film. The thermophysical properties of humid air calculated from the relationships given in Appendix A are reported in the first column of Table I. From these data, the following dimensionless parameters emerge: $\mathrm{Fr}=5.0310^{-8}, \mathrm{Le}=0.887, \mathrm{Pr}=0.71, H_{g}=47.7$.

When invoking the Boussinesq approximation, the thermal and solutal Rayleigh numbers based on the physical properties at initial state and maximum possible temperature and mass fraction differences are $R a_{T}=4.3110^{6}$ and $R a_{m}=1.3110^{6}(N \approx 0.3)$, showing predominance in heat transfer over mass transfer. The steady-state properties corresponding to humid air at uniform relative humidity and temperature equal to the wall temperature $\left(T_{w}=350 \mathrm{~K}\right)$ are reported in column 2 of Table I. Since the relative humidity at steady-state is reduced to $R H=50 \%$, the walls are dry and the mass fraction of water vapour increases up to $W_{v} \approx 0.1$. The increases both in temperature and mixture density lead to a larger increase in thermodynamic pressure (about 33\%). The purely thermodynamic predictions reported in column 2 of Table I were calculated numerically within a discrepancy less than $0.5 \%$, whatever the slope retained for the variation of the wall temperatures, provided that the initial conditions were those of column 1.

The evolutions of the average temperature and density are plotted in Fig. 3 for the four cases considered. The duration of the transient regime appears to be driven by the time required to reach a uniform mixture temperature. It takes about $20 \mathrm{~s}$ more 
than the duration of evaporation. For sudden increase in the wall temperatures, local supersaturation conditions ( $R H$ up to 200\%) are predicetd during few seconds in thin layers of hot fluid adjacent to the walls. By considering the temperature dependence of the critical supersaturation for homogeneous nucleation of water vapour in air [21], the validity of the present results for sudden change in wall temperature could thus be questionable. For $\delta t=20 s$, the peaks in supersaturation do not exceed $20 \%$ and are located close to the four cavity corners because the convective mixing of water vapour and dry air is the lowest in these regions. When the wall temperature increases slowly $(\delta t=120 \mathrm{~s})$, the supersaturation rates do not exceed $5 \%$ and stretch just for few seconds over corner regions of small extend.

Figure 4 shows the streamlines, isotherms, mass fraction and relative humidity isovalues for $\delta t=20,60$ and $120 \mathrm{~s}$ at times for which the mean mixture temperature is $\bar{T}=325 \mathrm{~K}$. At the beginning of the wall heating, thermosolutal convection develops quickly with the onset of a complex, multicellular flow structure. The heating of the fluid is produced by convective motions in the form of two large counter-rotating cells, symmetric about the cavity mid-plane, and strong Rayleigh-Bénard type cells just above the bottom wall. The clockwise circulations are plotted by full lines for the streamlines shown in Fig. 4 while dashed lines display counterclockwise circulations. On the other hand, the fluid is almost motionless below the central part of the top wall owing to the solutal and thermal stratifications prevailing in that region. As a consequence, the drying of the bottom wall occurs at first, as can be seen from the plot of the isolines of mass fraction reported in Fig. 4b and 4c. Similarities between temperature and mass fraction fields may thus not be found when a significant surface of the walls is dry, as exemplified in Fig.4c for the bottom wall. The top part of the cavity walls becomes progressively dry through a double-diffusive transfer which ends the evaporation process. Finally, the temperature becomes uniform within the cavity about $20 \mathrm{~s}$ after the full drying of the walls (Fig.3). It should be noted that rapid increases in the wall temperatures leads to strong recirculating flows, but low evaporation rates at times corresponding to an average mixture temperature of $325 \mathrm{~K}$. On the other hand, weaker fluid motion, more uniform temperature and mass fraction distributions are predicted when the decrease in wall temperatures is slower. Comparisons between Fig. 4a and 4c show also that the bottom wall is dryer for $\delta t=120 \mathrm{~s}$ than for 
$\delta t=20 \mathrm{~s}$ when the mean mixture temperature is $\bar{T}=325 \mathrm{~K}$. Since the mass of water evaporated is almost the same whatever $\delta t$ (see Fig. 3), it can be concluded that the decrease rate in the wall temperature has a large influence on the film thickness distributions.

The evolutions of the mean components of the Nusselt and Sherwood numbers at the vertical walls are shown in Fig. 5 for $\delta t=20 \mathrm{~s}$ and $120 \mathrm{~s}$. The latent component in the Nusselt number (Eq.32) is largely dominant at the beginning of evaporation. The latent energy required to evaporate the liquid water is indeed about ten times as much the sensible energy needed to increase the gas temperature from $300 K$ to $350 \mathrm{~K}$. The latent Nusselt number and the diffusive Sherwood numbers exhibit similar evolutions with peaks corresponding to the times at which the surfaces of the wall start to be dried. The reason is that the ratio $S h_{d i f f} / N u_{l v}$ follows the evolution of the wall saturation condition as Le $\left(1-W_{v, w}\right) / H_{g}$, which is merely constant with time. Figure 5 shows that the diffusive heat fluxes and advective mass fluxes are much smaller during the evaporation process. It can thus be concluded that the heat transfer is governed by phase change while the mass transfer is governed by mass diffusion. The reason is that the ratio $S h_{d i f f} / S h_{a d v}=\left(1-W_{v, w}\right) / W_{v, w}$ is large for the present values of the vapour mass fraction at the walls.

\subsubsection{Condensation.}

The initial conditions for the study of condensation were for a cavity filled with humid air $\left(W_{v, 0}=0.138\right.$ or $\left.R H_{0}=50 \%\right)$ at $T_{0}=350 \mathrm{~K}$. The four walls of the cavity were thus dry. The thermophysical properties of humid air are listed in column 3 of Table I. From these data, the following dimensionless parameters emerge: $\mathrm{Fr}=8.6710^{-8}$, Le $=0.846$, $\operatorname{Pr}=0.71, H_{g}=41.2$. For a problem formulation based on the Boussinesq approximation, the thermal and solutal Rayleigh numbers would be $R a_{T}=2.510^{6}$ and $R a_{m}=10^{6}$ (i.e. $\quad N=0.4$ ) The final steady-state conditions corresponding to humid air at uniform temperature $T_{\infty}=300 \mathrm{~K}$ are reported in the last column of Table I. The relative humidity at steady-state is $R H=100 \%$. The walls are completely wet because the mass fraction of water vapour at saturation conditions is $W_{v, s a t} \approx 0.031$. Therefore, $0.254 \mathrm{~g} / \mathrm{m}$ of water vapour are uniformly distributed within the humid air while $1.03 \mathrm{~g} / \mathrm{m}$ of liquid water are non-uniformly distributed over the wall surfaces. The decrease both in temperature and mixture density lead to a decrease in thermodynamic pressure of about $28 \%$. 
The evolutions of the average temperature and density are plotted in Fig. 6 for the four cases considered. The duration of the transient regime is now driven by the time required to obtain uniform saturation conditions $(R H=100 \%)$ within the cavity. Figure 6 shows that the time required to reach a constant mass of humid air is about $10 \mathrm{~s}$ more than that for the mean temperature. For sudden decrease in the wall temperature, local supersaturations occur for about $20 \mathrm{~s}$. Figure 7 shows the flow structure when the mean mixture temperature has reached $\bar{T}=325 \mathrm{~K}$ for the three cases $\delta t=20 \mathrm{~s}$, $60 \mathrm{~s}$ and $120 \mathrm{~s}$. The cooling of the fluid is first produced by convective motions in form of two large counter-rotating cells along the vertical walls, symmetric about the cavity mid-plane and with directions opposite to those for evaporation. Since the thermal and solutal forces are aiding, the hot and humid air coming from the core region flows downward along the cooled vertical walls, releasing heat and humidity. Strong Rayleigh-Bénard type cells below the top wall develop because the fluid in the core is hotter than the top wall.

It should be noted that the thicknesses of the liquid films are not the same at the four surfaces. About half of the mass of water vapour is condensed at the vertical walls while about one third is condensed at the top wall. Figure 8 shows the profiles of the thicknesses of the liquid films along the four walls at steady-state for the case $\delta t=120 \mathrm{~s}$. These profiles are almost independent of the time for the decrease in the wall temperature. The convective motions associated with the two Rayleigh-Bénard cells at the top region produce two symmetric maximums and a minimum in the thickness of the liquid film at the top wall. The thicknesses of the vertical liquid films exhibit a maximum at the upper part of the walls where the mass and heat transfer coefficients are the largest during the transient regime.

The evolutions of the mean Sherwood number at the vertical walls displayed in Fig.9 present similar profiles as those for evaporation. Since the relationships between the Nusselt and Sherwood components discussed for evaporation are still valid, we have only plotted in Fig. 9 the Sherwood number evolutions along the vertical walls. The mass of water vapour condensed at the vertical walls being almost independent of the duration of the transient regime (differences less than $4 \%$ ), the time integration of the variations of $\overline{S h}(t)$ 
for $\delta t=20 s$ and $120 s$ are almost equal. The same is true for the Nusselt numbers and a time integration of the heat fluxes at the four wall yields the latent energy transferred to the walls equal to $2404 \mathrm{~J} / \mathrm{m}$, and the sensible energy equal to $216 \mathrm{~J} / \mathrm{m}$ and $211 \mathrm{~J} / \mathrm{m}$ for $\delta t=20 s$ and $120 s$, respectively.

\subsection{Periodic variations of the wall temperature.}

When the wall temperature varies periodically around a mean temperature $T_{w, m}=\left(T_{w, h}+\right.$ $\left.T_{w, c}\right) / 2$ with a temperature difference $\Delta T=\left(T_{w, h}-T_{w, c}\right)$, the dimensional temperature may be written as

$$
T_{w}(t)=T_{w, m}+\frac{\Delta T}{2} \cos \left(\frac{2 \pi t}{t_{p}}\right)
$$

where $t_{p}$ is the period of the wall temperature oscillations. The computations discussed in this subsection were carried out for $T_{w, m}=325 \mathrm{~K}$ and $\Delta T=50 \mathrm{~K}$ on a $256 \times 256$ uniform grid. The time step has been selected to obtain more than 10,000 steps in the oscillation period (for example, $\Delta t=5 \cdot 10^{-3} s$ for $t_{p}=60 \mathrm{~s}$ ).

Figure 10a shows the time variations of the wall temperature and of the mixture mean temperature over the first five periods for $t_{p}=60 \mathrm{~s}$. The cavity is initially filled with hot, humid air at $T_{0}=350 \mathrm{~K}$ and $R H=50 \%$. Condensation occurs as soon as the wall temperature falls below the dew point temperature. In this case, the relative humidity reaches $R H=100 \%$ before the end of the first-half-period and the four walls are partially wetted. For $t \geq 30 \mathrm{~s}$, evaporation at the wet walls begins. The mean mixture temperature being not equal to the wall temperature at the end of the first and subsequent periods, the initial conditions for the second period are changed compared to the initial conditions. The walls are dry but there is still a weak convective motion within the cavity due to the phase lag of the oscillatory mean temperature. These differences in the transient behaviour of $\bar{T}$ and $T_{w}$ are reduced when increasing the period. For $t_{p}=60 \mathrm{~s}$, the results show that the oscillation in the mean mixture temperature may be written as

$$
\left.\bar{T}(t) \approx\left(T_{w, m}-0.6\right)+\left(\frac{\Delta T}{2}-0.8\right) \cos \left[2 \pi(t-2.32) / t_{p}\right)\right]
$$

This equation indicates that the mean mixture temperature oscillates around the mean 
wall temperature, with an amplitude slightly smaller than that of the wall temperature, and with a small phase lag. The reason is that the period $\left(t_{p}=60 \mathrm{~s}\right)$ is of same order of magnitude than the characteristic times for heat or mass diffusion $\left((L / 2)^{2} / a_{0} \approx 125 s\right.$ and $\left.(L / 2)^{2} / D_{a v, 0} \approx 75 s\right)$. On the other hand, computations not discussed here have shown that chaotic thermosolutal flows may arise if the period of the wall temperature variation is of the order or less than $t_{p}=1 \mathrm{~s}$. From Fig. 10b, it can be seen that the mean density and thermodynamic pressure variations are time-periodic with a phase lag close to the one displayed for the mean temperature. On the other hand, the amplitude of the variations in thermodynamic pressure being $\Delta \bar{P}=0.275 \bar{P}_{0}$, the relative change in pressure is higher than those for temperature and density because the decreases in temperature and density occur almost simultaneously. The oscillation in the thermodynamic pressure may be approximated by:

$$
\left.\bar{P}(t) \approx \bar{P}_{m}+\frac{\Delta \bar{P}}{2} \cos \left[2 \pi(t-2.96) / t_{p}\right)\right]
$$

where $\bar{P}_{m}=0.861 \bar{P}_{0}$. From this relation, the work done by the pressure force over half a period is thus $(\bar{P}(t+t p / 2)-\bar{P}(t)) \Omega=\Delta \bar{P} \Omega=278,6 \mathrm{~J} / \mathrm{m}$. It has been checked that this energy is approximately equal to the sensible heat transferred by diffusion to the four walls during the same time interval. Therefore, the decrease or increase in the internal energy during half a period is distributed between the sensible heat diffusion through the thermal boundary layers and the reversible work of the pressure force (negative when $T_{w}$ decreases and positive otherwise). Figure 10c shows that the phase lag of $\bar{N} u$ against wall temperature oscillation is about $\pi / 2$ and that the two components of the Nusselt number oscillate almost in phase. Just before the end of each period, the vertical walls become completely dry. The walls keep dry for about $7.5 s$ (i.e. $\left.\approx t_{p} / 8\right)$.

A fully-established oscillating solution, independent of the initial state, may be assumed obtained at the end of the third period. For the following periods, the initial state corresponding to $T_{w}=350 \mathrm{~K}$ (i.e. $t_{0}=n t_{p}$, with $n \geq 3$ ) is shown in Fig. 11a in the form of contour plots of the streamlines, isotherms, mass fraction and relative humidity isolines. Owing to the period and phase lag, the mixture temperature and mass fraction are not uniform at $t=t_{0}$. As a result, there exists a weak convective motion above the bottom wall. This motion is purely thermal since there is a stable solutal stratification while the thermal 
stratification between the bottom wall and the core of the cavity is unstable. At $t=t_{1}$ (Fig. 11b), the wall temperature is decreased to $325 \mathrm{~K}$. Layers of cold air along the four wall are predicted while hot and humid air is still present in the central part of the cavity. The fluid motion consists thus in two convective counter-rotating cells along the vertical walls. Between $t=t_{1}$ and $t=t_{2}$, the cavity core is hotter than the fluid near the walls, leading to an unstable stratification near the top wall and the appearance of Rayleigh-Bénard cells which are still present at $t=t_{2}$. At $t=t_{2}$ (Fig. 11c), the bulk of the fluid is almost at the wall temperature $\left(T_{w}=300 \mathrm{~K}\right)$ and saturated, except below the top wall where hotter, supersaturated mixture pockets are observed. It should be emphasized that the decrease in temperature between $t=t_{0}$ and $t=t_{2}$ is also produced by the quite large decrease in thermodynamic pressure. Since the decrease in internal energy due to the pressure force is uniformly distributed within the cavity (on account of the low Mach-number assumption), it is believed that this energy loss is the main reason for the occurrence of supersaturation peaks. In comparison with the condensation period, Figure 11d shows that the fluid motion reverses and is amplified during the evaporation period. Stronger cells are seen along both the vertical and bottom walls. As a result, the drying of the bottom wall occurs at first.

Figure 12 shows the thickness distributions of the liquid water films at the four walls. Firstly, it can be seen that the top wall (Fig. 12a) is not completely dried at the beginning of the period $\left(t=t_{0}\right)$. Furthermore the liquid film thickness, with two symmetrical maxima and one minimum at the center of the top wall, over most of the period, faithfully reflects the existence of the two convective cells. The trace of the two convective rolls is clear on the top wall because the mass fraction of the water vapour is maximum at the top of the cavity, since water vapour is lighter than dry air. On the other hand, the flat distribution of the liquid thickness for $t=t_{1}$ is in agreement with the flow structure shown in Fig. 11b. The vertical and bottom walls are completely dried at $t=t_{0}$. The main differences in the film thickness distributions displayed in Fig. $12 \mathrm{~b}$ and 12c may be summarized as follows: the vertical walls are quickly dried over the last quarter of the period (from $t_{3}$ to $t_{0}+t_{p}$ ) while the bottom wall is wetted just around the time interval corresponding to the minimum in wall temperature (i.e. around $t_{2}$ ). Like for the top wall, the thickness distributions along the vertical walls reflect the flow structure, including the change in the direction of the recirculating motions associated with condensation and evaporation. 
The evolutions of the mass of liquid water at the four walls, the water vapour mass and the overall mixture mass within the cavity during one period are presented in Fig. 13. As expected, these results show that the overall mass conservation is satisfied at any time. The mass of vapour is minimum when the mass of liquid is maximum, while the sum is time independent. The total mass of liquid water condensed at the two vertical walls is the largest and that at the bottom wall is the smallest. The maximum in the mass of liquid condensed at the four walls occurs few seconds after the time for the minimum in wall temperature $\left(t=t_{2}\right)$, the phase difference being the largest at the top wall. The bottom wall is dry for about half a period, the vertical walls for about a quarter of a period, while the top wall is dry just during $\approx 3 \mathrm{~s}$. A small amount of liquid water remains few seconds after the peak in wall temperature $\left(T_{w}=350 \mathrm{~K}\right.$ at $\left.t=t_{0}\right)$ showing that evaporation continues when temperature starts to decrease.

\subsection{Effect of aspect ratio.}

In this section we are considering the effects of the cavity aspect ratio on condensation. The linear decrease in the wall temperatures from $350 \mathrm{~K}$ to $300 \mathrm{~K}$ occurs during $\delta t=60 \mathrm{~s}$. The initial conditions are similar to those considered in section 4.1 and the computations were carried out until steady state.

Two cases were considered. First, the cavity width was maintained constant $(L=10 \mathrm{~cm})$ while the height was varied from $H=5 \mathrm{~cm}$ to $H=20 \mathrm{~cm}$. It is the procedure generally followed to investigate the effect of aspect ratio for thermosolutal convection. Second, the aspect ratio was changed while the volume of the cavity was kept constant. In that case, the Froude number changes.

When changing the aspect ratio through increases in $H$, the mass of liquid water condensed at the four walls is proportional to $H$ because the final thermodynamic state is the same $\left(m_{\text {water }}=\left(\bar{\rho}_{0}-\bar{\rho}_{\infty}\right) H L\right)$. Consequently the average thickness of the liquid film increases with $H$ for a constant L. For example, the average thickness of the liquid film for $A=2$ is two times larger than for $A=0.5$. Indeed, $e_{m}=\kappa / 6, \kappa / 4$ and $\kappa / 3$ for 
$A=0.5,1$ and 2 , respectively, with $\kappa=\left(\bar{\rho}_{0}-\bar{\rho}_{\infty}\right) L / \rho_{\text {water }}$. It could thus be expected that the condensation period would increase with $H$, unless the strength of the thermosolutal convection is enough to compensate for this increase in film thicknesses.

Figure 14 shows the evolutions the total mass of liquid condensed at the walls for the three aspect ratios considered. During the first 20 seconds, convection is mainly thermal because the wall temperature is above the dew point temperature $\left(T_{d p} \approx 333 \mathrm{~K}\right.$ ) while the gradients in the mass fraction fields caused by the temperature differences are small. The sharp increase in the water condensed after this first period is linked to strong convective circulations. Since the slope of the curves gives a global view of the strength of convection, it can be concluded that the fluid circulations are amplified as the height of the cavity is increased. For example, the maximum in the dimensionless streamfunction fields shifts from 6 to 22 when $A$ is increased from 0.5 to 2 . The plateau is mainly for the purely diffusive period. That result is exemplified in Fig. 14 by considering the times $t_{d}$ at which the almost flat variations in the mass of liquid are reached. From an inspection of various flow variables, we have assumed that it is relevant to consider that thermosolutal convection turns into diffusion when the maximum in mass fraction and temperature differences within the cavity are less than $\Delta W_{v, \max }=1.3310^{-3}$ and $\Delta T_{\max }=0.2 \mathrm{~K}$, respectively. It is indicated in Fig. 14 that the end of the convective regime increases from $t_{d}=70 \mathrm{~s}$ to $t{ }^{\prime \prime}=100 s$ when $A$ increases from 0.5 to 2 . Since the mass of water vapour condensed is twice greater for $A=2$, it can be concluded that the speed of the phase change process increases with the aspect ratio. On the other hand, larger aspect ratios lead to larger duration of the diffusive regime toward steady state (the times $t_{\infty}$ shown in Fig.5 are based on the criteria $\Delta W_{v, \max }=1.3310^{-5}$ and $\left.\Delta T_{\max }=2.10^{-3} \mathrm{~K}\right)$.

Variations of the aspect ratio from $A=0.25$ to $A=4$, with the volume kept constant at $\Omega=10^{-2} \mathrm{~m}^{3} / \mathrm{m}$, correspond to $5 \mathrm{~cm} \leq H, L \leq 20 \mathrm{~cm}$. The Froude number increases thus from $\mathrm{Fr}=1.0810^{-8}$ to $\mathrm{Fr}=6.9410^{-7}$ as $A$ increases from $A=0.25$ to $A=4$. Since the mass of water vapour condensed is the same $\left(m_{\text {water }}=1.03 \mathrm{~g}\right)$ the steady-state thermodynamic pressure is the same $\left(\bar{P}_{\infty}=0.716 \mathrm{~atm}\right)$. The Rayleigh-Bénard cells below the top wall (see Fig. 7) still exist for $A=0.5,1$ and 2 but not for $A=0.25$ and $A=4$ : in these last two cases, the flow circulations consist in two counter-rotating cells along the vertical walls with a width of $L / 2$ (i.e $2.5 \mathrm{~cm}$-width for $A=4$ and $10 \mathrm{~cm}$ for $A=0.25$ ). 
As a consequence, the variations in the water film thickness along the top wall are very different, as it can be seen in Fig. 15. The thickness is maximum at the center of the top wall for $A=0.25$ and $A=4$ while it is minimum for the other aspect ratios. Finally, the repartitions of the mass of water vapour condensed at the walls are given in Table II. As expected, the mass of water at the vertical walls increases with the aspect ratio while the opposite is observed at the bottom and top walls. The difference between the masses of water at the top and bottom walls is maximum for $A=1$ owing to the two Rayleigh-Bénard cells below the top wall.

\section{CONCLUSION}

Transient wall evaporation and condensation in a cavity due to time variations in the wall temperature were investigated by using a low-Mach number model and by taking into account variations of the mixture properties. Despite the rather small temperature and mixture density differences involved in the present study restricted to humid air, such a modelling is required owing to large variations in thermodynamic pressure and possible large variations in mixture properties. Extensions to other condensable species carried by a non-condensable carrier gas are straightforward through changes in the formulae used to evaluate the thermophysical properties of the mixture according to temperature and mass (mole) fraction. The main limitations of the present study are the use of a laminar flow model and that no fog formation is taken into account. Therefore, the modelling is restricted to low local supersaturations.

The model allows however time-dependent computations of the mass and thickness distributions of thin liquid films at the walls during condensation as well as during evaporation. By starting the computations from a well defined thermodynamic state, it has been shown that the final state predicted by elementary thermodynamic calculations is reached, whatever the time variations in the wall temperatures. These results and the discussed comprehensive physical results obtained give confidence in the present computations.

The computations were first carried out for linear variations of the wall temperature in order to shed light on the different flow structures occuring during condensation or evaporation. These differences are mainly due to the change in the direction of the buoyancy forces, 
which are aiding in both cases owing to the lower molecular weight of water vapour. For periodic variations in the wall temperature, the averaged field quantities oscillates between the cases previously considered with small phase lags while the heat and mass transfers at the walls exhibit rather different periodic behaviours.

Finally, the effects of the cavity aspect ratio on the increase rate of the liquid films condensed at the walls are studied. When the cavity width is kept constant while the cavity height is increased, the duration of the convective condensation period does not vary much while the subsequent period of diffusive condensation is longer. For cavities of constant volume but different aspect ratios, the thickness distributions of the water films greatly varies according to the different convective patterns encountered.

\section{Acknowledgments}

The authors wish to thank the CNRS-IDRIS Computer Center for making computational facilities available through grant \# $09-1265$. 


\section{References}

[1] T.F. Lin,T.F. Lin, C.J. Chang, W.M. Yan, Analysis of combined buoyancy effects of thermal and mass diffusion on laminar forced convection heat transfer in a vertical tube, ASME J. Heat Transfer 110 (1988) 337-344.

[2] V. Dharma Rao, V. Murali Krishna, K.V. Sharma, P.K. Sarma, A theoretical study on convective condensation of water vapour from humid air in turbulent flow in a vertical duct, ASME J. Heat Transfer 129 (2007)1627-1637.

[3] V. Dharma Rao, V. Murali Krishna, K.V. Sharma, P.V.J. Mohana Rao, Convective condensation of vapor in the presence of a non-condensable gas of high concentration in laminar flow in a vertical pipe, Int. J. Heat Mass Transfer 51 (2008) 6090-6101.

[4] T.F Lin, C.C. Huang, T.S. Chang, Transient binary mixture natural convection in square enclosures, Int. J. Heat Mass Transfer 33 (1990) 287-299.

[5] C. Béghein, F. Haghighat, F. Allard, Numerical Study of double-diffusive natural convection in a square cavity, Int. J. Heat Mass Transfer 35 (1992) 833-846.

[6] V.A.F. Costa, Double diffusive natural convection in a square enclosure with heat and mass diffusive walls, Int. J. Heat Mass Transfer 40 (1997) 4061-4071.

[7] G.D. McBain, Natural convection with unsaturated humid air in vertical cavities, Int. J. Heat Mass Transfer 40 (1997) 3005-3012.

[8] J.A. Weaver, R. Viskanta, Natural convection due to horizontal temperature and concentration gradients - 1. Variable thermophysical properties effects, Int. J. Heat Mass Transfer 34 (12) (1991) 3107-3120.

[9] J.A. Weaver, R. Viskanta, Natural convection due to horizontal temperature and concentration gradients - 2. Species interdiffusion, Soret and Dufour effects, Int. J. Heat Mass Transfer 34 (12) (1991) 3121-3133.

[10] W.M. Yan, T.F. Lin, C.J. Chang, Combined heat and mass transfer in natural convection between vertical parallel plates, Wärme und Stoffübertragung, 23 (1988) 69-76. [11] N. Laaroussi, G. Lauriat, Conjugate thermosolutal convection and condensation of humid air in cavities, Int. J. Thermal Sciences 47(12) (2008) 1571-1586.

[12] O. Laguerre, S. Benamara, D. Remy, D. Flick, Experimental and numerical study of heat and moisture transfers by natural convection in a cavity filled with solid obstacles, Int. J. Heat Mass Transfer 52 (12) (2009) 5691-5700.

[13] G. Wang, Q-W; Wang, M. Zeng, H. Ozoe, Natural convection heat transfer in an 
inclined porous cavity under time-periodic boundary conditions with positive/negative inclined angles, J. Porous Media 11(6) (2008) 541-555.

[14] E.V. Kalabin, M.V. Kanashina, P.T. Zubkov, Natural-convective heat transfer in a square cavity with time-varying side-wall temperature, Num. Heat Transfer, Part A, 47 (2005) 621-631.

[15] E.V. Kalabin, M.V. Kanashina, P.T. Zubkov, Heat transfer from the cold wall of a square cavity to the hot one by oscillatory natural-convection, Num. Heat Transfer, Part A, 47 (2005) 609-619.

[16] K. H. Chung, H.S. Kwak, J.M. Hyun, Finite-wall effect on buoyant convection in an enclosure with pulsating exterior surface temperature, Int. J. Heat Mass Transfer 44 (2001) 721-732.

[17] D.L. Sun, Z.G. Qu, Y.L. He, W.Q. Tao, An efficient segregated algorithm for incompressible fluid flow and heat transfer problems - IDEAL (Inner Doubly iterative Efficient Algorithm for Linked equations). - Part 1: Mathematical formulation and solution procedure, Numerical Heat Transfer, Part B 53 (2008) 1-17.

[18] H. Sun, G. Lauriat, On the heat and mass transfer analogy for natural convection of non-dilute binary mixtures of ideal gases in cavities, Comptes Rendus Mcanique, 337 (3) (2009) 141-149.

[19] H. Sun, G. Lauriat, A numerical study based on a weakly-compressible formulation for thermosolutal convection in vertical cavities, Heat and Mass Transfer, DOI-10.1007/s00231010-587-5.

[20] H. Sun, G. Lauriat, D.L. Sun, W.Q. Tao, Transient double-diffusive convection in an enclosure with large density variations, Int. J. Heat Mass Transfer 53 (2010) 615-625.

[21] D. E. Rosner, M. Epstein, Fog formation conditions near cool surfaces, J. Colloid Interface Science 28 (1968) 60-65.

[22] N. Schaeffer, F. Utheza, F. Garnier, G. Lauriat, Stable stratification alteration in a thermal cloud chamber, J. Chem. Phys. 113 (2000) 8085-8092.

[23] F. Utheza, D. Sénéchal, F. Garnier, Buoyancy-driven convective motion in a thermal diffusion cloud chamber using a water/helium mixture, Int. J. Thermal Sciences 48 (2009) 1043-1048.

[24] D.R. Lide, H.V. Kehiaian, CRC Handbook of thermophysical and thermochemical data, CRC Press 1994 


\section{APPENDIX}

\section{A. Thermophysical properties}

\section{Air and water vapor}

The properties of dry air and water vapor are calculated by using the following equations given by Lide and Kehiaian [24] for the range [273K, 600K]

- Dynamic viscosity:

$$
\mu=A_{1} T+A_{2} T^{2}+A_{3} T^{3}+A_{4} T^{4} \quad\left(k g m^{-1} s^{-1}\right)
$$

\begin{tabular}{|c|c|c|c|c|c|}
\hline & $\mu$ at $298.15 K$ & $A_{1}$ & $A_{2}$ & $A_{3}$ & $A_{4}$ \\
\hline Dry air & $18.510^{-6}$ & $7.7248810^{-8}$ & $-5.9523810^{-11}$ & $2.7136810^{-14}$ & --- \\
\hline Water vapor & $9.910^{-6}$ & $5.7510010^{-8}$ & $-1.7363710^{-10}$ & $3.9013310^{-13}$ & $-2.6902110^{-16}$ \\
\hline
\end{tabular}

TABLE I: Coefficients of the polynomial expansion for dynamic viscosity.

- Thermal conductivity:

$$
k=A_{1} T+A_{2} T^{2}+A_{3} T^{3}+A_{4} T^{4} \quad\left(W m^{-1} K^{-1}\right)
$$

\begin{tabular}{|c|c|c|c|c|c|}
\hline & k at $298.1 \mathrm{~K}$ & $A_{1}$ & $A_{2}$ & $A_{3}$ & $A_{4}$ \\
\hline Dry air & $26.110^{-3}$ & $0.96510^{-4}$ & $-9.96010^{-9}$ & $-9.31010^{-11}$ & $8.88210^{-14}$ \\
\hline Water vapor & $18.610^{-3}$ & $0.34910^{-4}$ & $1.51110^{-7}$ & $-2.576 \quad 10^{-10}$ & $2.05010^{-13}$ \\
\hline
\end{tabular}

TABLE II: Coefficients of the polynomial expansion for thermal conductivity.

- Heat capacity:

+ Dry air:

$$
C_{p, a}=1000.0+2.510^{-7} T^{3} \quad\left(J K^{-1} k^{-1}\right)
$$


+ Water vapor:

$$
C_{p, v}=A_{0}+A_{1} T+A_{2} T^{2}+A_{3} T^{3} \quad\left(J K^{-1} k^{-1}\right)
$$

\begin{tabular}{|c|c|c|c|c|c|}
\hline & $C_{p, v}$ at $298.15 K$ & $A_{0}$ & $A_{1}$ & $A_{2}$ & $A_{3}$ \\
\hline Water vapor & 1866.1 & 1877.8 & -0.4417 & $1.56810^{-3}$ & $-7.28610^{-7}$ \\
\hline
\end{tabular}

TABLE III: Coefficients for water vapor heat capacity.

- Latent heat of condensation of water vapor at the wall temperature (thin film approximation):

$$
h_{l v}=2.7554 \times 10^{6}-3.464 T_{w}^{2} \quad\left(J k g^{-1}\right)
$$

- Saturation vapor pressure :

$$
P_{H_{2} 0, s a t}=10^{5} \exp \left(18.79-0.0075 T-\frac{5965.6}{T}\right)
$$

where $T$ is in Kelvin and $P_{H_{2} 0, \text { sat }}$ in Pa.

- Dew point temperature corresponding to the partial pressure $P_{H_{2} 0}$ of the water vapor

$$
T_{d}=66.67\left(B-\sqrt{B^{2}-178.968}\right)
$$

where $B=18.79-\ln \left(10^{-5} P_{H_{2} 0}\right), T$ in Kelvin and $P_{H_{2} 0}$ in Pa.

\section{Mixtures}

- Relative humidity :

$$
R H=\frac{P_{v}}{P_{v, s a t}}=\frac{x_{v} \bar{P}}{P_{v, s a t}}
$$

where $x_{v}$ is the mole fraction of vapor obtained from the mass fraction of vapor as

$$
x_{v}=\frac{W_{v}}{W_{v}+M^{*}\left(1-W_{v}\right)}
$$

The properties of the gas mixture are evaluated as functions of those of air and vapor by using the following equations given by Rao et al. [3]. 
- Dynamic viscosity:

$$
\mu=\frac{\left(\sqrt{18} \mu_{v} x_{v}+\sqrt{29} \mu_{a} x_{a}\right)}{\left(\sqrt{18} x_{v}+\sqrt{29} x_{a}\right)} \quad\left(N s m^{-2}\right)
$$

- Thermal conductivity:

$$
k=\frac{x_{v} k_{v}}{\left(x_{v}+x_{a} A\right)}+\frac{x_{a} k_{a}}{\left(x_{a}+x_{v} A\right)} \quad\left(W m^{-1} K^{-1}\right)
$$

where

$$
A=\frac{\left[0.8876\left(1+\sqrt{k_{v} / k_{a}}\right)\right]^{2}}{3.6}
$$

- Heat Capacity:

$$
C_{p}=\left(1-W_{v}\right) C_{p, a}+W_{v} C_{p, v} \quad\left(J k g^{-1} K^{-1}\right)
$$

Since the fluctuating part of the motion pressure is assumed negligible in comparison with the thermodynamic pressure when invoking the low-Mach number approximation, the diffusion coefficient of water vapor in air, $D_{a v}$, was calculated using the following equation as function of the thermodynamic pressure $\bar{P}$ and local temperature $T$ of the mixture

$$
D_{a v}=\frac{1.87 \times 10^{-10} \times T^{2.072}}{\bar{P}}\left(m^{2} s^{-1}\right)
$$




\section{TABLES}

\begin{tabular}{|c|c|c||c|c|}
\hline & \multicolumn{2}{|c||}{ evaporation } & \multicolumn{2}{c|}{ condensation } \\
\hline & $P_{0}=101,325 \mathrm{~Pa}$ & $P_{\infty}=134,848 \mathrm{~Pa}$ & $P_{0}=101,325 \mathrm{~Pa}$ & $P_{\infty}=72,591 \mathrm{~Pa}$ \\
& $T_{0}=300 \mathrm{~K}$ & $T_{\infty}=350 \mathrm{~K}$ & $T_{0}=350 \mathrm{~K}$ & $T_{\infty}=300 \mathrm{~K}$ \\
& $H R=100 \%$ & $H R=50 \%$ & $H R=50 \%$ & $H R=100 \%$ \\
\hline$W_{v}$ & 0.0219 & 0.1016 & 0.1380 & 0.0308 \\
\hline$x_{v}$ & 0.0348 & 0.1539 & 0.2048 & 0.0486 \\
\hline$\mu\left(k g m^{-3}\right)$ & 1.1611 & 1.2640 & 0.9304 & 0.8274 \\
\hline$k\left(k g m^{-1} s^{-1}\right)$ & $1.831410^{-5}$ & $1.973610^{-5}$ & $1.933010^{-5}$ & $1.821910^{-5}$ \\
\hline$C_{p}\left(k J \mathrm{~m}^{-1} \mathrm{~K}^{-1}\right)$ & 0.0264 & 0.0306 & 0.0307 & 0.0265 \\
\hline$D_{a v}\left(\mathrm{~m}^{2} \mathrm{~s}^{-1}\right)$ & 1025.6 & 1099.3 & 1131.1 & 1033.2 \\
\hline$h_{l v}\left(J \mathrm{~kg}^{-1}\right)$ & $2.50410^{-5}$ & $2.59010^{-5}$ & $3.44710^{-5}$ & $3.49610^{-5}$ \\
\hline
\end{tabular}

TABLE I: Thermophysical properties of humid air for the four thermodynamic states corresponding to the initial and steady-state conditions investigated.

\begin{tabular}{|c|c|c|c|c|c|}
\hline Aspect ratio & $A=0.25$ & $A=0.5$ & $A=1$ & $A=2$ & $A=4$ \\
\hline Left or right wall & 0.099 & 0.186 & 0.264 & 0.362 & 0.417 \\
\hline Top wall & 0.494 & 0.444 & 0.372 & 0.230 & 0.151 \\
\hline Bottom wall & 0.337 & 0.215 & 0.130 & 0.077 & 0.046 \\
\hline
\end{tabular}

TABLE II: Overall masses of liquid water (in $g / m$ ) at the four walls according to the aspect ratio for cavities of same volume $\left(\Omega=10^{-2} \mathrm{~m}^{3} / \mathrm{m}\right)$. 


\section{FIGURE CAPTIONS}

Figure 1. Schematic of the rectangular enclosure and temperature boundary conditions.

Figure 2. Evolution of the average mixture density (a) and Sherwood number (b) according to the grid resolution.

Figure 3. Evaporation: variations versus time of the average mixture temperature (a) and density (b) corresponding to the four cases investigated for evaporation. The filled circles correspond to the density values at the times for $\bar{T}=325 \mathrm{~K}$.

Figure 4. Evaporation: streamlines $\left[\psi_{\min }(4) \psi_{\max }\right]$, isotherms in Kelvin $\left[T_{\min }(1 K) T_{\max }\right]$, mass fraction $\left[W_{\min }(0.002) W_{\max }\right]$ and relative humidity isolines $\left[R H_{\min }(2 \%) R H_{\max }\right]$ for an average mixture temperature $\bar{T}=325 K$ according to the duration of the increase in wall temperatures.

Figure 5. Evaporation: evolutions of the mean Nusselt and Sherwood components (Eqs. 34 and 38) along the vertical walls for $\delta t=2 s$ and $\delta t=120 \mathrm{~s}$.

Figure 6. Condensation : variations versus time of the average mixture temperature (a) and density (b) corresponding to the four cases investigated for condensation (Fig. 3b).

Figure 7. Condensation : streamlines $\left[\psi_{\min }(4) \psi_{\max }\right]$, isotherms in Kelvin $\left[T_{\min }(0.5 K)\right.$ $\left.T_{\max }\right]$, mass fraction $\left[W_{\min }(0.005) W_{\max }\right]$ and relative humidity isolines $\left[R H_{\min }(2 \%) R H_{\max }\right]$ for an average mixture temperature $\bar{T}=325 \mathrm{~K}$ according to the duration of the decrease in wall temperatures.

Figure 8. Condensation: profiles of the liquid film thicknesses along the walls at steady state for $\delta t=120 \mathrm{~s}$.

Figure 9. Condensation: evolutions of the mean Sherwood components along the vertical walls for $\delta t=20 s$ and $\delta t=120 s$.

Figure 10. Periodic evolutions of the wall and mean mixture temperatures (a), dimensionless thermodynamic pressure and mean density (b), and mean Nusselt number components at the vertical walls $(\mathrm{c})$.

Figure 11. Streamlines $\left[\psi_{\min }(1) \psi_{\max }\right]$, isotherms in Kelvin $\left[T_{\min }(1 K) T_{\max }\right]$, mass fraction $\left[W_{\min }(0.01) W_{\max }\right]$ and relative humidity isolines $\left[R H_{\min }(0.05 \%) R H_{\max }\right]$ at four equally spaced times along a period of oscillation.

Figure 12. Film thickness distributions along the walls at times $t_{0}$ to $t_{3}$ corresponding to 
the scalar fields shown in Fig. 13.

Figure 13. Time variations of the mass of liquid water at the walls and of the mixture mass in one time period.

Figure 14. Time variation of the mass of liquid water condensed at the four walls according to the aspect ratio for constant width of the cavity $\left(L=0.1 \mathrm{~m} . t_{d}\right.$ and $t_{\infty}$ indicate the beginning and the end of the diffusion period.

Figure 15. Steady-state thickness distribution of the liquid film at the top wall for five aspect ratios and constant volume of the cavity $\left(\Omega=10^{-2} \mathrm{~m}^{3} / \mathrm{m}\right)$.

* Electronic address: hsun01@univ-mlv.fr

$\dagger$ Electronic address: lauriat@univ-mlv.fr

$\ddagger$ Electronic address: nicolas@univ-mlv.fr 


\section{FIGURES}

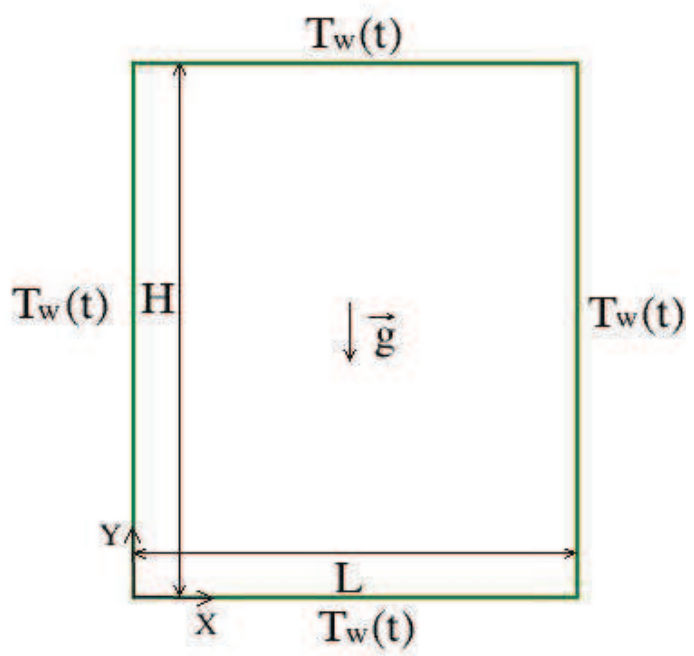

Figure 1: Schematic of the rectangular enclosure and boundary conditions.

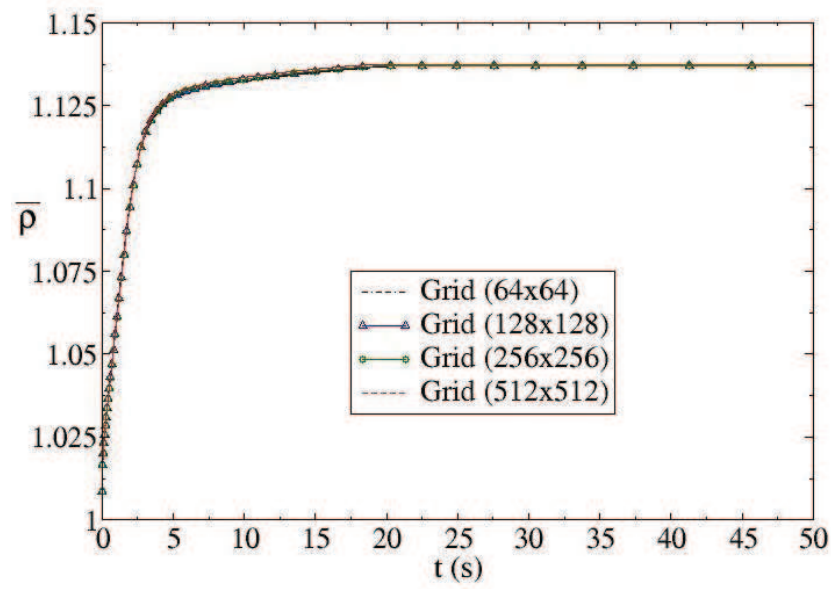

(a)

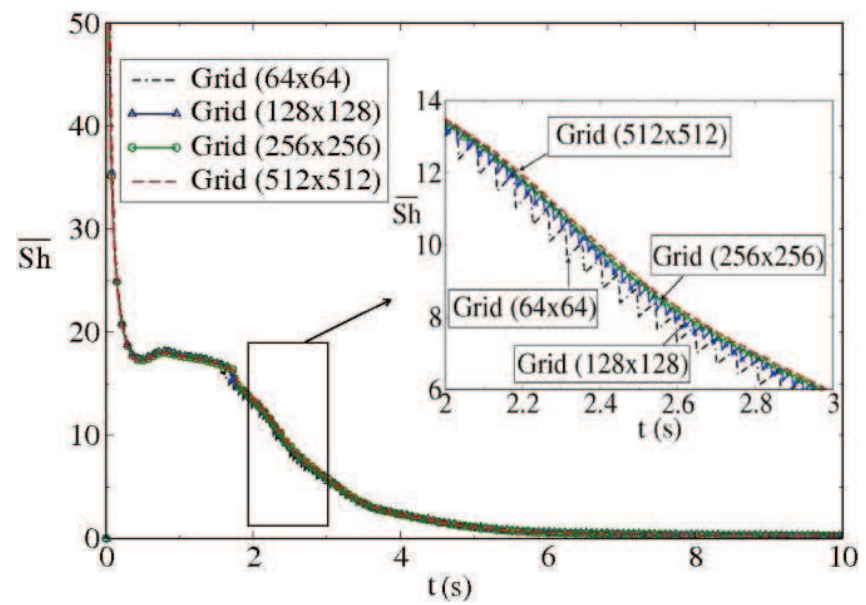

(b)

Figure 2. Evolution of the average mixture density (a) and Sherwood number (b) according to the grid resolution 


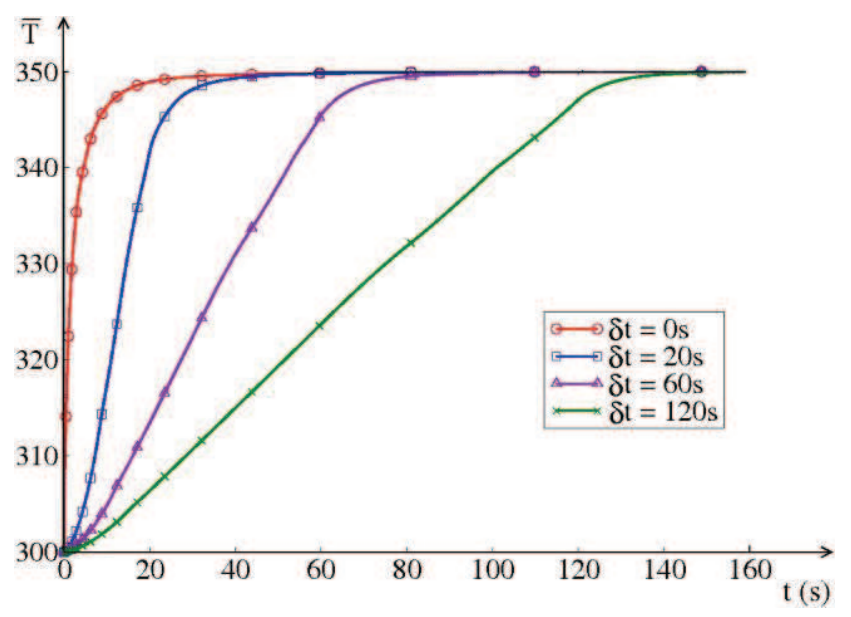

(a)

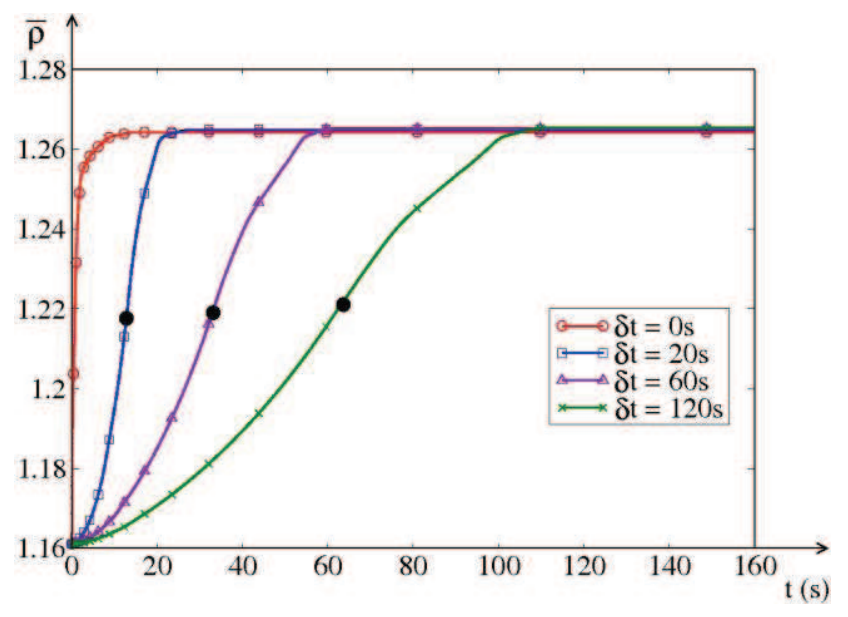

(b)

Figure 3. Evaporation: variations versus time of the average mixture temperature (a) and density (b) corresponding to the four cases investigated for evaporation (Fig.3a). The filled circles correspond to the density values at the times when $\bar{T}=325 \mathrm{~K}$. 

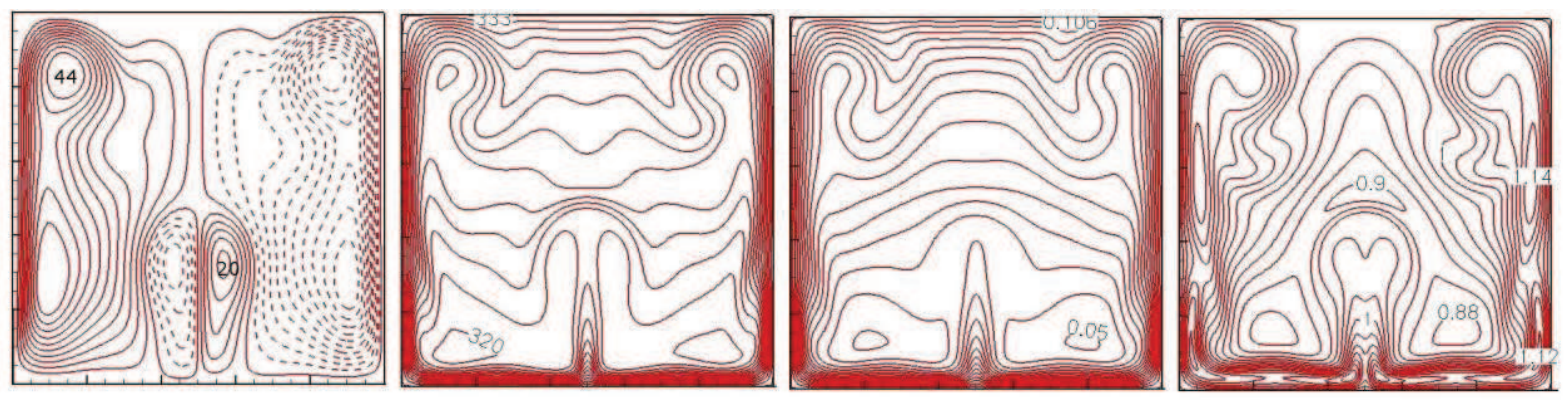

(a) $\delta \mathrm{t}=20 \mathrm{~s}$

$\left(\left|\psi_{\min }\right|=\psi_{\max }=46.4\right),\left(\mathrm{T}_{\min }=319.6 \mathrm{~K}, \mathrm{~T}_{\max }=333.1 \mathrm{~K}\right),\left(\mathrm{W}_{\min }=0.049, \mathrm{~W}_{\max }=0.11\right),\left(\mathrm{RH}_{\min }=\right.$ $87 \%, \mathrm{RH}_{\max }=114 \%$ )
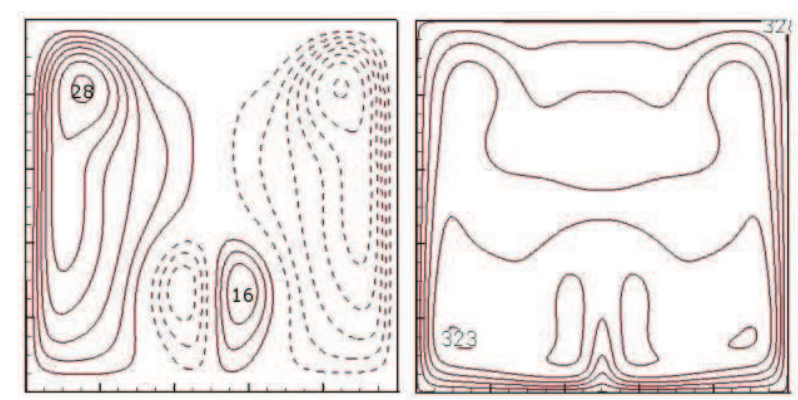
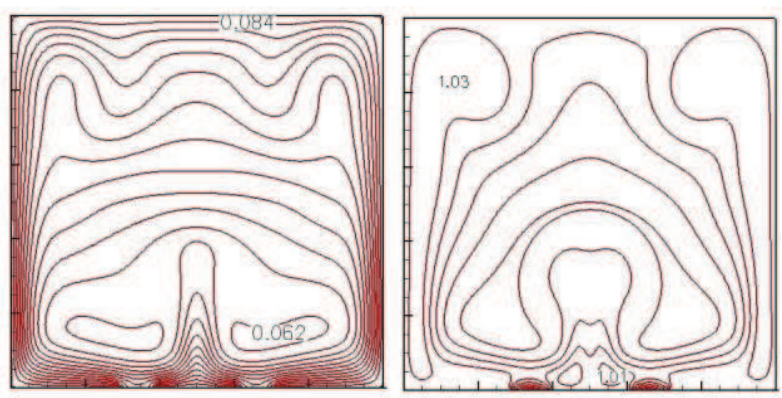

(b) $\delta \mathrm{t}=60 \mathrm{~s}$

$\left(\left|\psi_{\min }\right|=\psi_{\max }=28.9\right),\left(\mathrm{T}_{\min }=322.8 \mathrm{~K}, \mathrm{~T}_{\max }=328.1 \mathrm{~K}\right),\left(\mathrm{W}_{\min }=0.062, \mathrm{~W}_{\max }=0.086\right)$, $\left(\mathrm{RH}_{\min }=87 \%, \mathrm{RH}_{\max }=103 \%\right)$
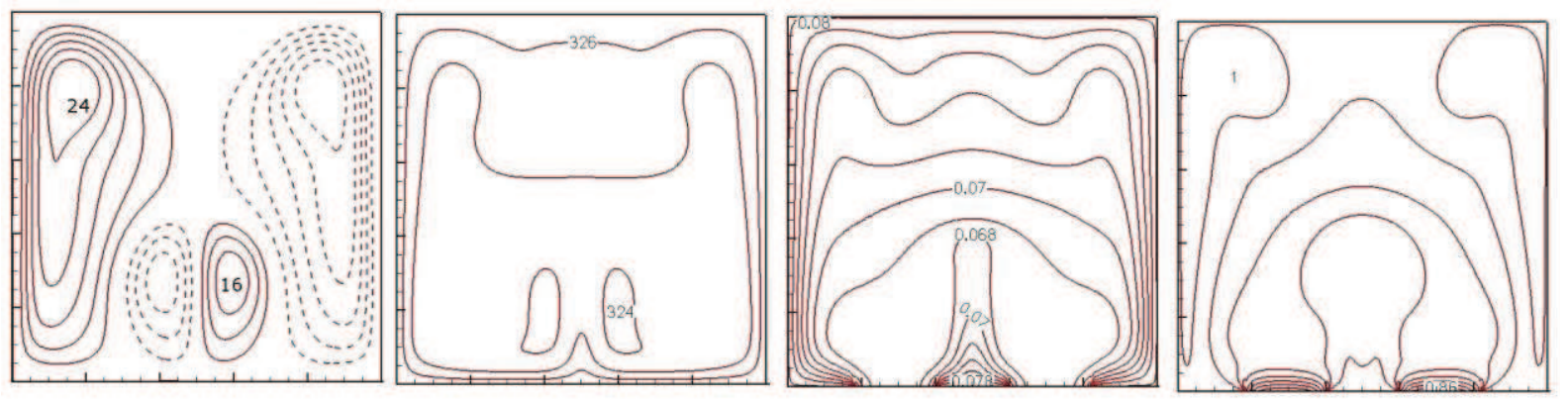

(c) $\delta \mathrm{t}=120 \mathrm{~s}$

$\left(\left|\psi_{\min }\right|=\psi_{\max }=24.1\right),\left(\mathrm{T}_{\min }=323.9 \mathrm{~K}, \mathrm{~T}_{\max }=326.7 \mathrm{~K}\right),\left(\mathrm{W}_{\min }=0.066, \mathrm{~W}_{\max }=0.080\right)$, $\left(\mathrm{RH}_{\min }=84 \%, \mathrm{RH}_{\max }=100 \%\right)$

Figure 4. Evaporation: streamlines $\left[\psi_{\min }(4) \psi_{\max }\right]$, isotherms in Kelvin $\left[\mathrm{T}_{\min }(1 \mathrm{~K}) \mathrm{T}_{\max }\right.$, mass fraction $\left[\mathrm{W}_{\min }(0.002) \mathrm{W}_{\max }\right.$ ] and relative humidity isolines $\left(\mathrm{RH}_{\min }(2 \%) \mathrm{RH}_{\max }\right)$ for an average mixture temperature $\bar{T}=325 \mathrm{~K}$ according to the duration of the increase in wall temperatures. 


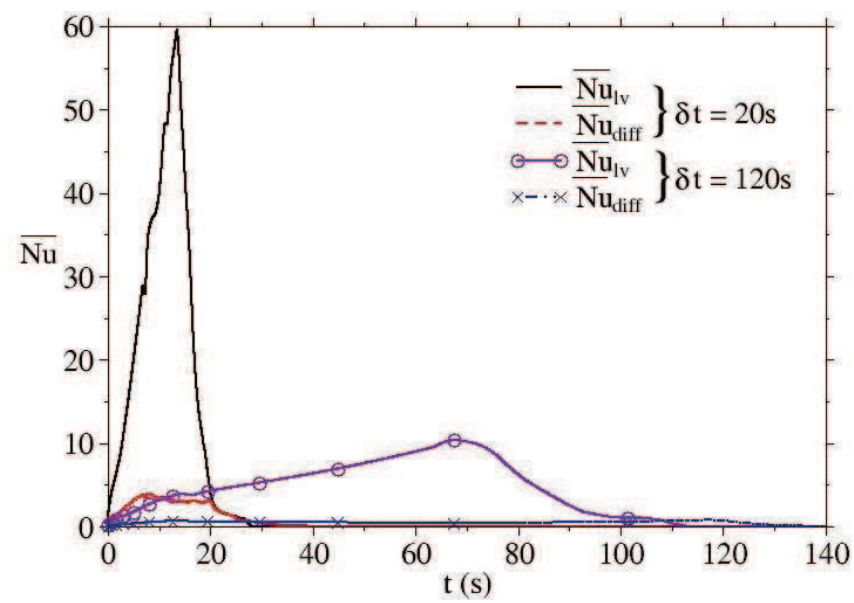

(a)

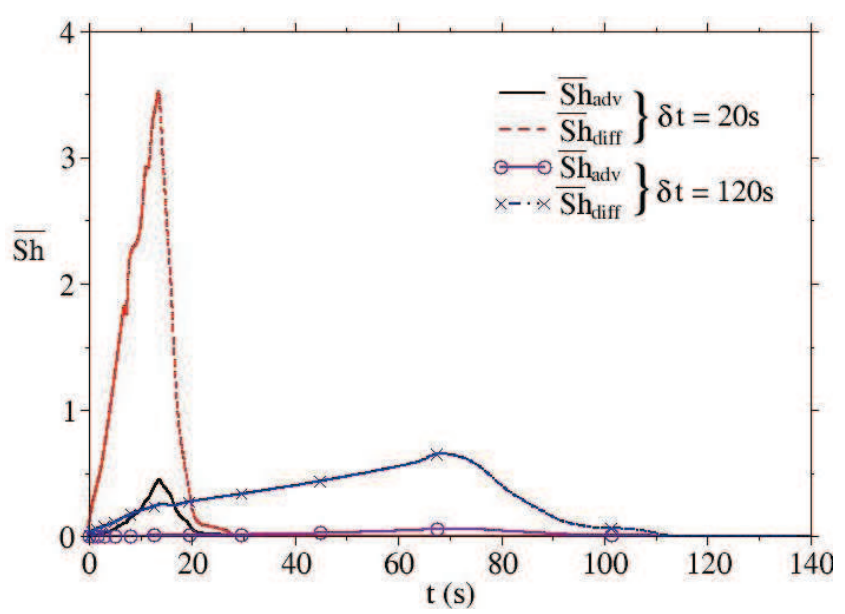

(b)

Figure 5. Evaporation: evolutions of the mean Nusselt and Sherwood components (Eqs. 34 and 35) along the vertical walls for $\delta \mathrm{t}=20 \mathrm{~s}$ and $\delta \mathrm{t}=120 \mathrm{~s}$. 


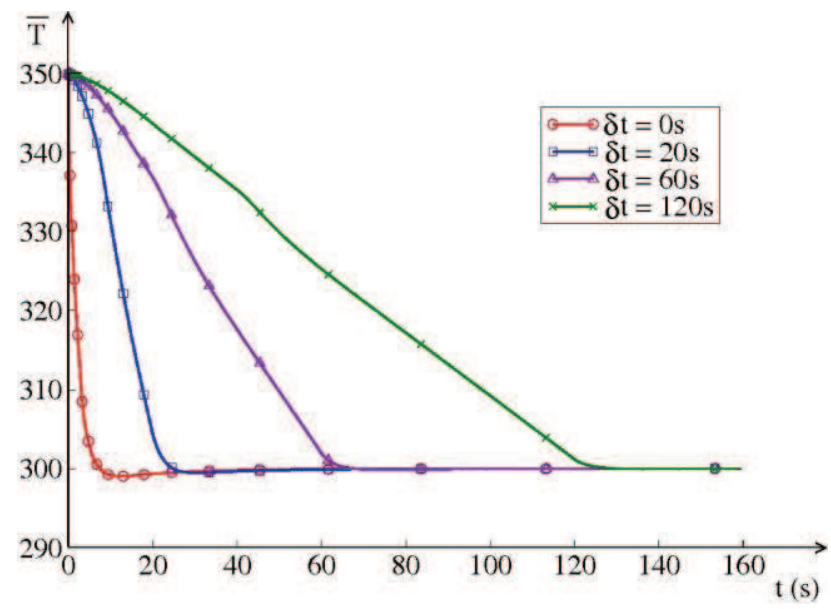

(a)

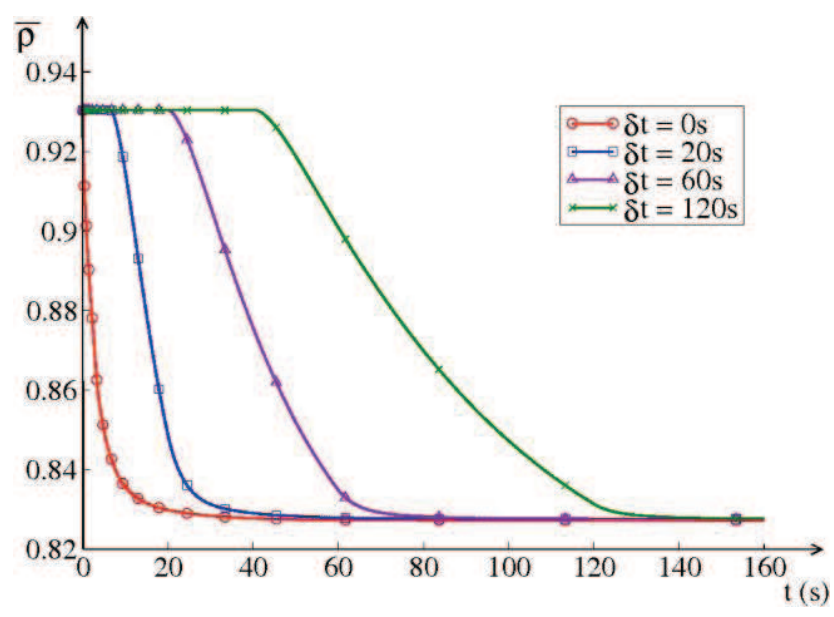

(b)

Figure 6.Condensation: variations versus time of the average mixture temperature (a) and density (b) corresponding to the four cases investigated for condensation (Fig. 3b). 

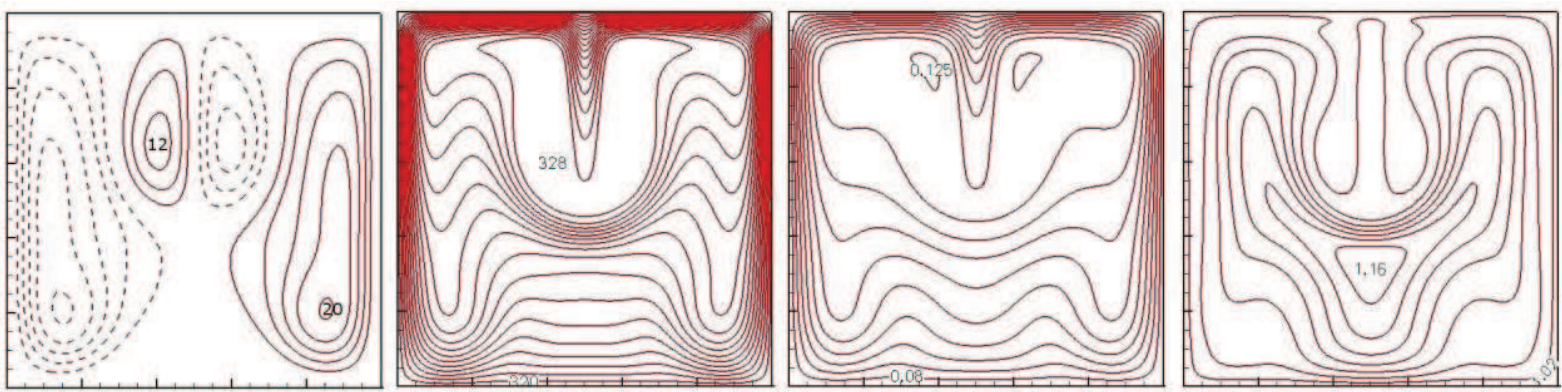

(a) $\delta \mathrm{t}=20 \mathrm{~s}$

$\left(\left|\psi_{\min }\right|=\psi_{\max }=20.3\right),\left(\mathrm{T}_{\min }=319.6 \mathrm{~K}, \mathrm{~T}_{\max }=329.1 \mathrm{~K}\right),\left(\mathrm{W}_{\min }=0.075, \mathrm{~W}_{\max }=0.125\right)$,

$\left(\mathrm{RH}_{\min }=100 \%, \mathrm{RH}_{\max }=116 \%\right)$
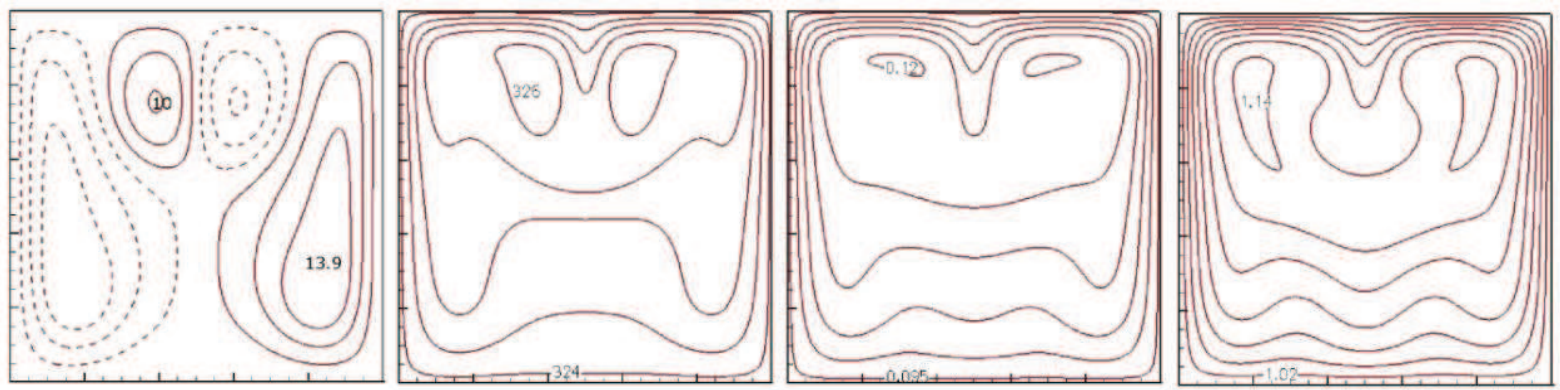

(b) $\delta \mathrm{t}=60 \mathrm{~s}$

$\left(\left|\psi_{\min }\right|=\psi_{\max }=13.9\right),\left(\mathrm{T}_{\min }=322.9 \mathrm{~K}, \mathrm{~T}_{\max }=326.2 \mathrm{~K}\right),\left(\mathrm{W}_{\min }=0.094, \mathrm{~W}_{\max }=0.120\right)$, $\left(\mathrm{RH}_{\min }=100 \%, \mathrm{RH}_{\max }=114 \%\right)$
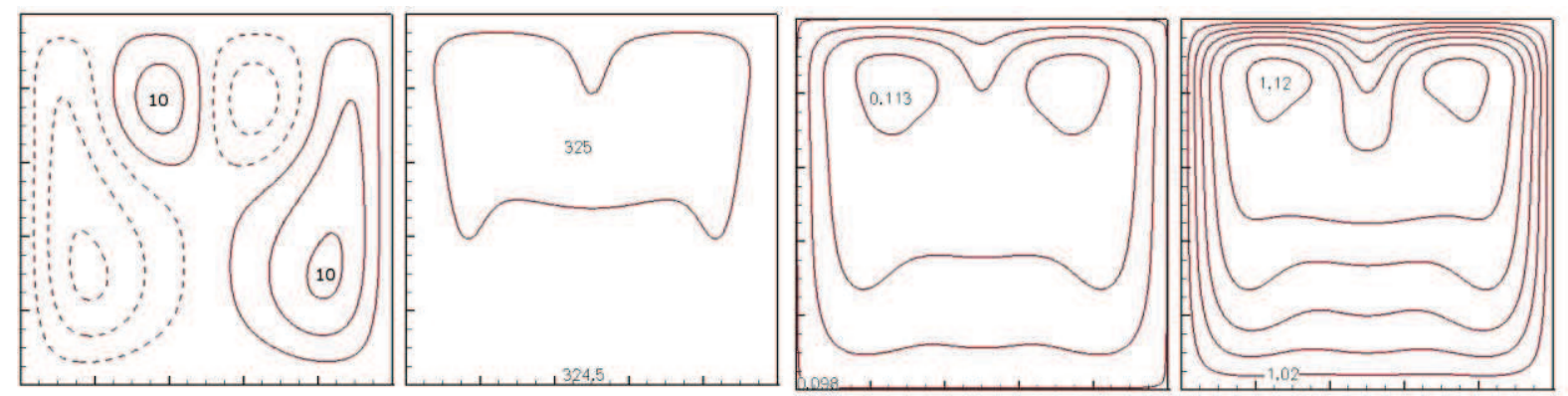

(c) $\delta \mathrm{t}=120 \mathrm{~s}$

$\left(\left|\psi_{\min }\right|=\psi_{\max }=10.8\right),\left(\mathrm{T}_{\min }=324.5 \mathrm{~K}, \mathrm{~T}_{\max }=325.2 \mathrm{~K}\right),\left(\mathrm{W}_{\min }=0.098, \mathrm{~W}_{\max }=0.114\right)$, $\left(\mathrm{RH}_{\min }=100 \%, \mathrm{RH}_{\max }=112 \%\right)$

Figure 7. Condensation: streamlines $\left[\psi_{\min }(4) \psi_{\max }\right]$, isotherms in Kelvin $\left[\mathrm{T}_{\min }(0.5 \mathrm{~K}) \mathrm{T}_{\max }\right]$, mass fraction $\left[\mathrm{W}_{\min }(0.005) \mathrm{W}_{\max }\right]$ and relative humidity isolines $\left(\mathrm{RH}_{\min }(2 \%) \mathrm{RH}_{\max }\right)$ for an average mixture temperature $\bar{T}=325 \mathrm{~K}$ according to the duration of the decrease in wall temperatures. 


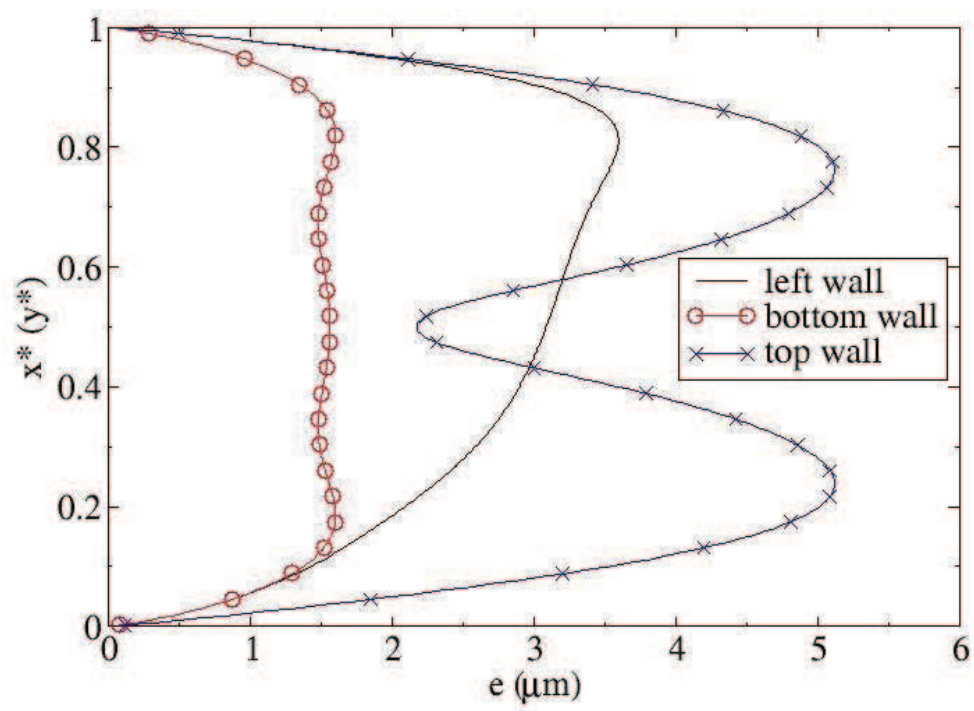

Figure 8. Condensation: Profiles of the liquid film thicknesses along the walls at steady state for $\delta \mathrm{t}=120 \mathrm{~s}$.

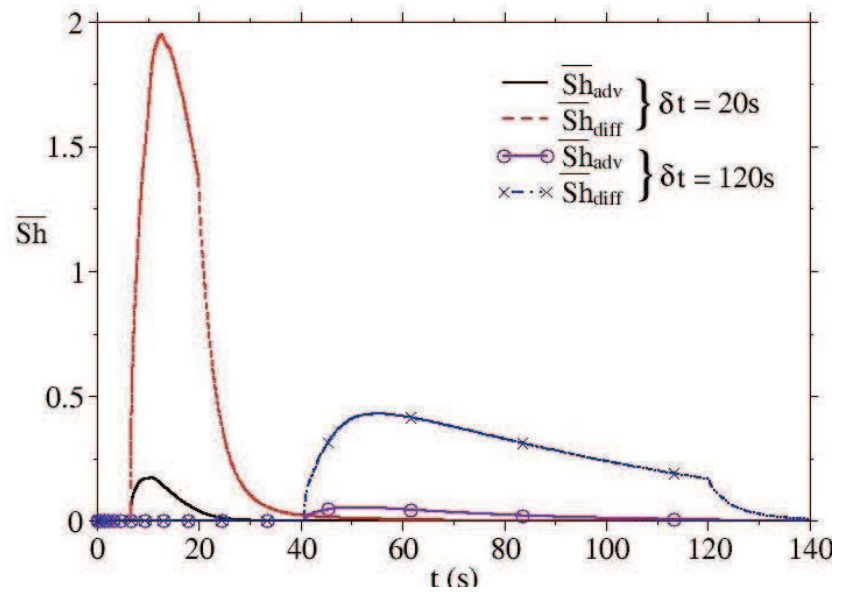

Figure 9. Condensation: evolutions of the mean Sherwood components along the vertical walls for $\delta \mathrm{t}=20 \mathrm{~s}$ and $\delta \mathrm{t}=120 \mathrm{~s}$. 


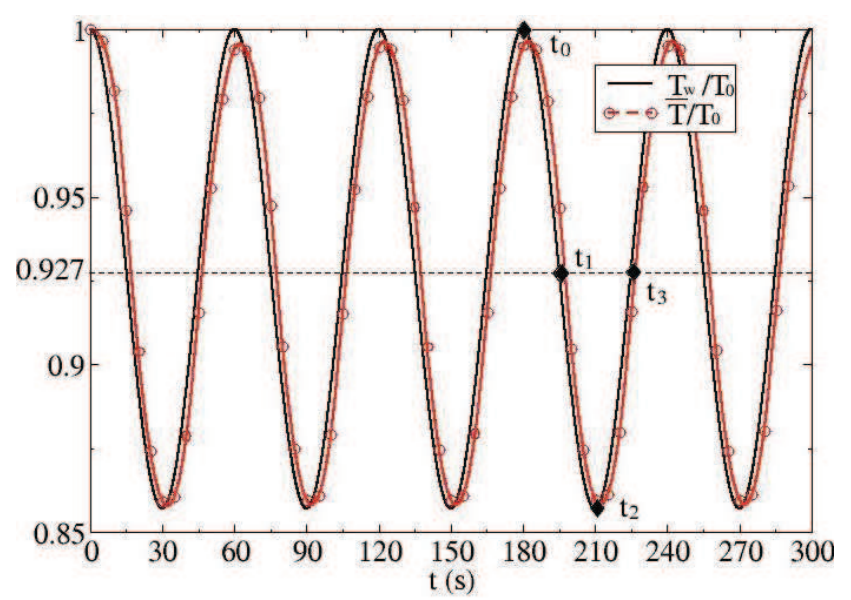

(a)

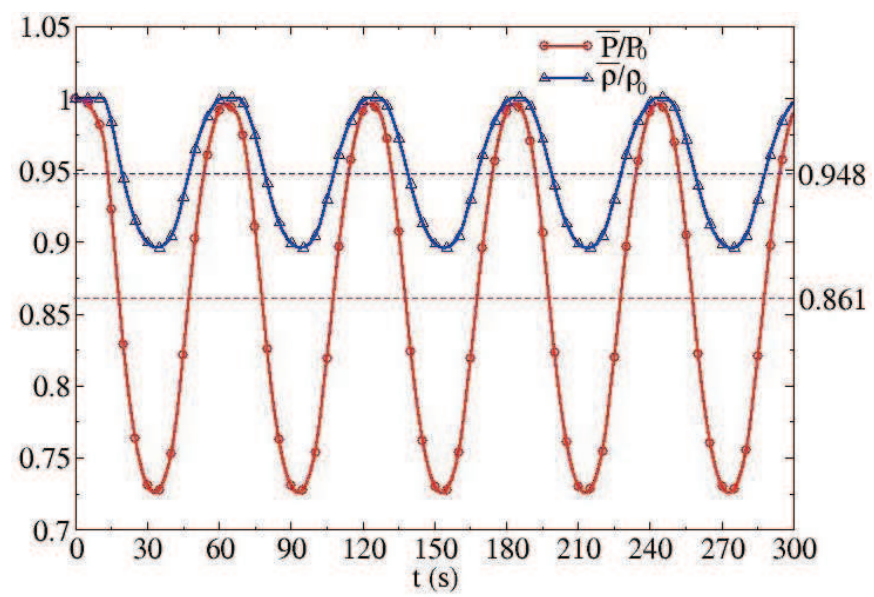

(b)

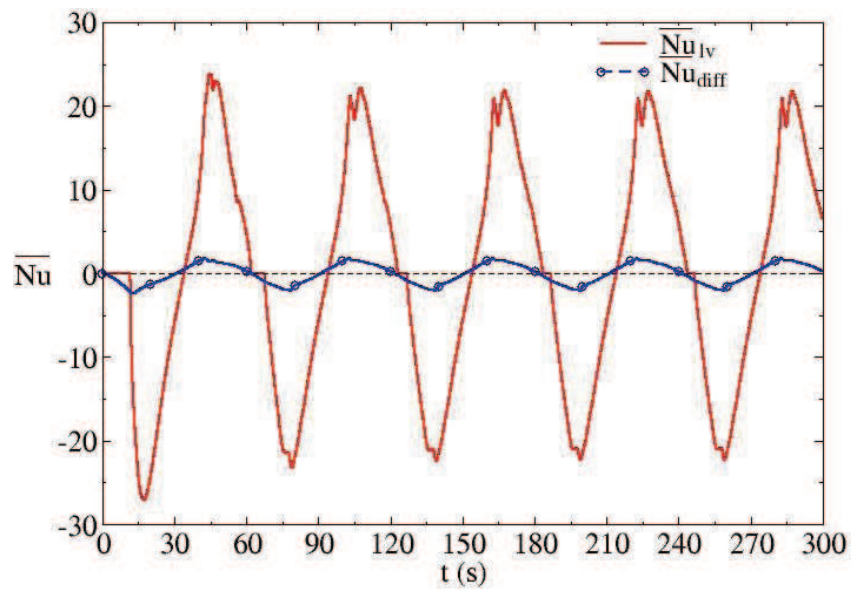

(c)

Figure 10. Periodic evolutions of the wall and mean mixture temperatures (a), of the dimensionless thermodynamic pressure and mean density (b), and of the mean Nusselt number at the vertical walls (c). 

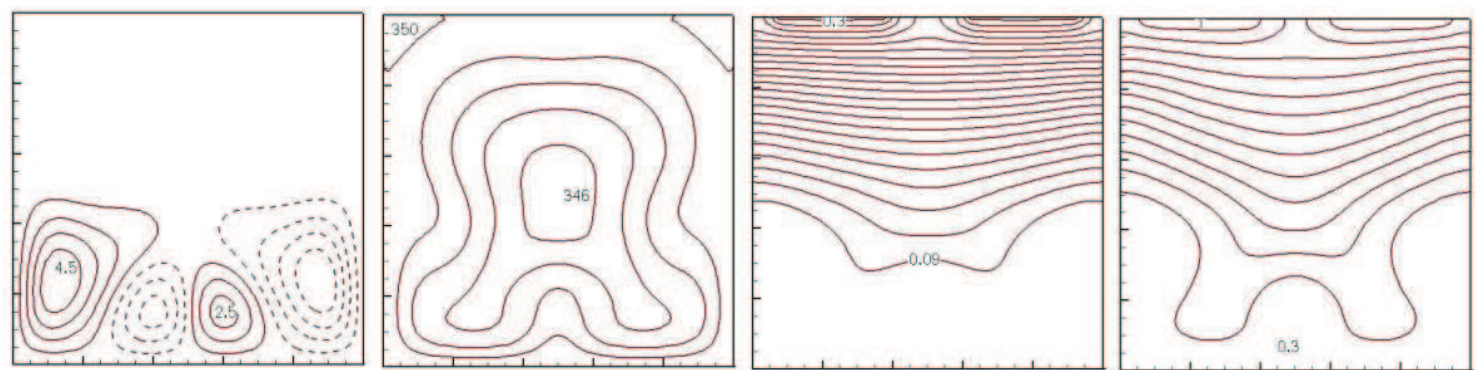

(a) $\mathbf{t}=\mathbf{t}_{\mathbf{0}}$

$\left(\left|\psi_{\min }\right|=\psi_{\max }=4.39\right),\left(\mathrm{T}_{\min }=345.5 \mathrm{~K}, \mathrm{~T}_{\max }=350 \mathrm{~K}\right),\left(\mathrm{W}_{\min }=0.08, \mathrm{~W}_{\max }=0.305\right),\left(\mathrm{RH}_{\min }=30 \%\right.$, $\left.\mathrm{RH}_{\max }=100 \%\right)$
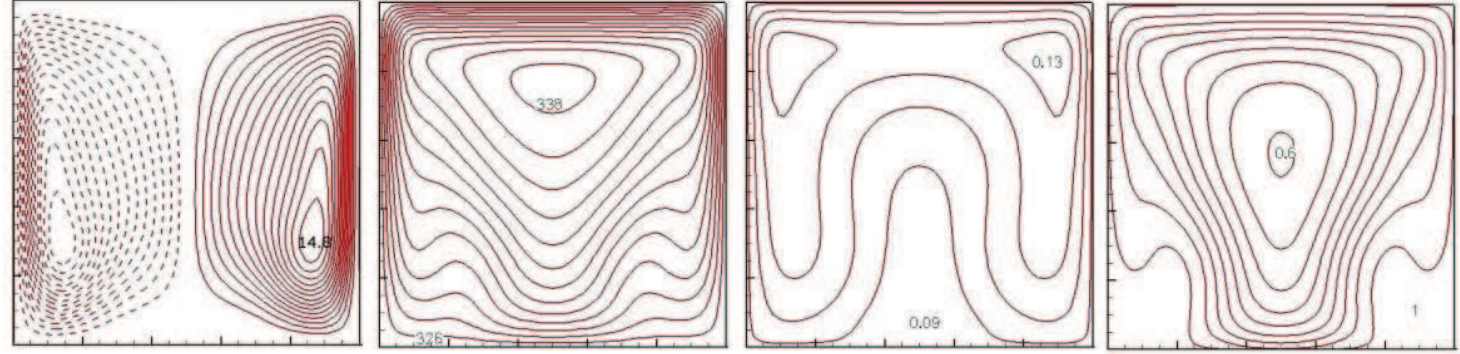

(b) $\mathbf{t}=\mathbf{t}_{\mathbf{1}}=\mathbf{t}_{\mathbf{0}}+\mathbf{t}_{\mathbf{p}} / \mathbf{4}$

$\left(\left|\psi_{\min }\right|=\psi_{\max }=14.84\right),\left(\mathrm{T}_{\min }=325.1 \mathrm{~K}, \mathrm{~T}_{\max }=338.3 \mathrm{~K}\right),\left(\mathrm{W}_{\min }=0.09, \mathrm{~W}_{\max }=0.135\right),\left(\mathrm{RH}_{\min }=60 \%\right.$, $\left.\mathrm{RH}_{\max }=100 \%\right)$
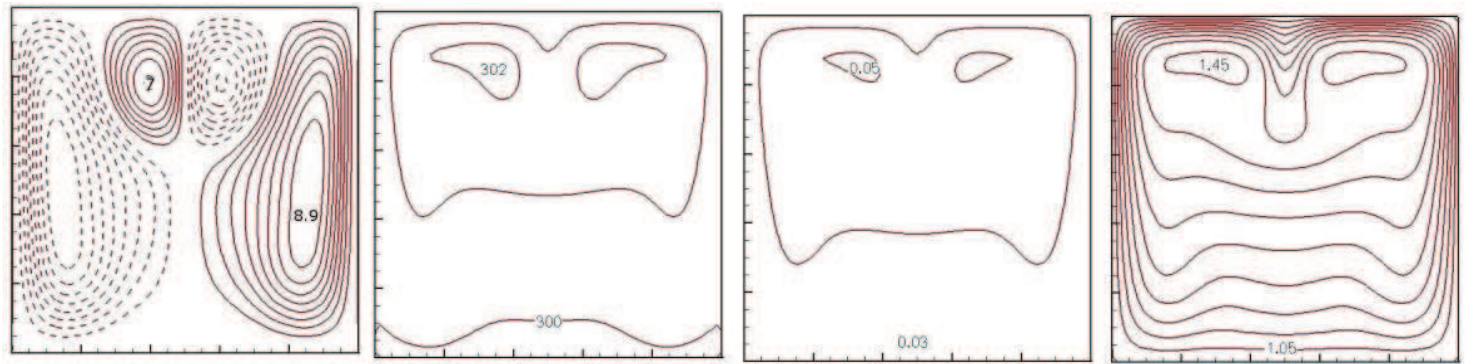

(c) $\mathbf{t}=\mathbf{t}_{2}=\mathbf{t}_{\mathbf{0}}+\mathbf{t}_{\mathbf{p}} / \mathbf{2}$

$\left(\left|\psi_{\min }\right|=\psi_{\max }=8.9\right),\left(\mathrm{T}_{\min }=300 \mathrm{~K}, \mathrm{~T}_{\max }=302.15 \mathrm{~K}\right),\left(\mathrm{W}_{\min }=0.03, \mathrm{~W}_{\max }=0.05\right),\left(\mathrm{RH}_{\min }=\right.$ $\left.99.7 \%, \mathrm{RH}_{\max }=146 \%\right)$
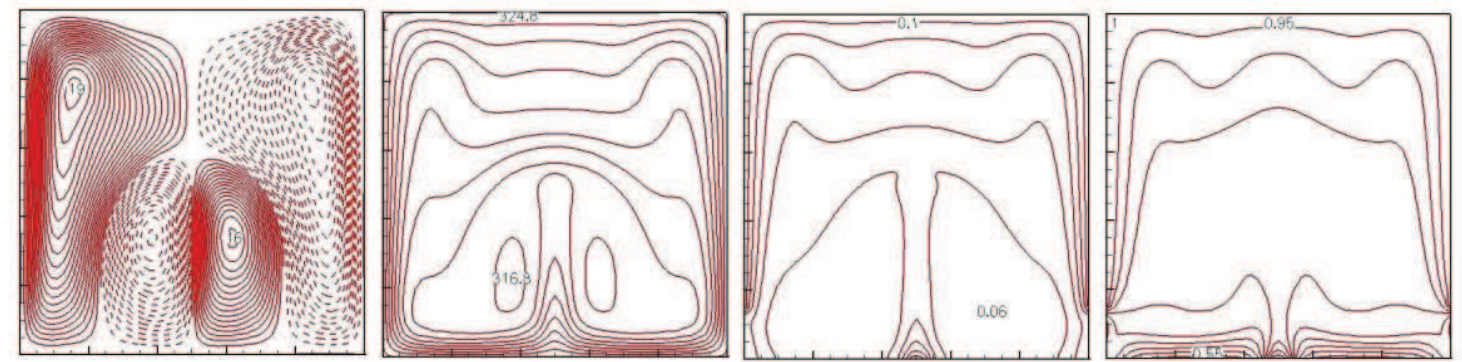

(d) $\mathbf{t}=\mathbf{t}_{\mathbf{3}}=\mathbf{t}_{\mathbf{0}}+\mathbf{3} \mathbf{t}_{\mathrm{p}} / \mathbf{4}$

$\left(\left|\psi_{\min }\right|=\psi_{\max }=19.45\right),\left(\mathrm{T}_{\min }=316.6 \mathrm{~K}, \mathrm{~T}_{\max }=324.9 \mathrm{~K}\right),\left(\mathrm{W}_{\min }=0.055, \mathrm{~W}_{\max }=0.107\right),\left(\mathrm{RH}_{\min }=52.7 \%\right.$, $\left.\mathrm{RH}_{\max }=100 \%\right)$

Figure 11. Streamlines $\left[\psi_{\min }(1) \psi_{\max }\right]$, isotherms in Kelvin $\left[\mathrm{T}_{\min }(1 \mathrm{~K}) \mathrm{T}_{\max }\right]$, mass fraction $\left[\mathrm{W}_{\min }(0.01) \mathrm{W}_{\max }\right]$ and relative humidity isolines $\left[\mathrm{RH}_{\min }(0.05 \%) \mathrm{RH}_{\max }\right]$ at four equally spaced times along a period of oscillation. 


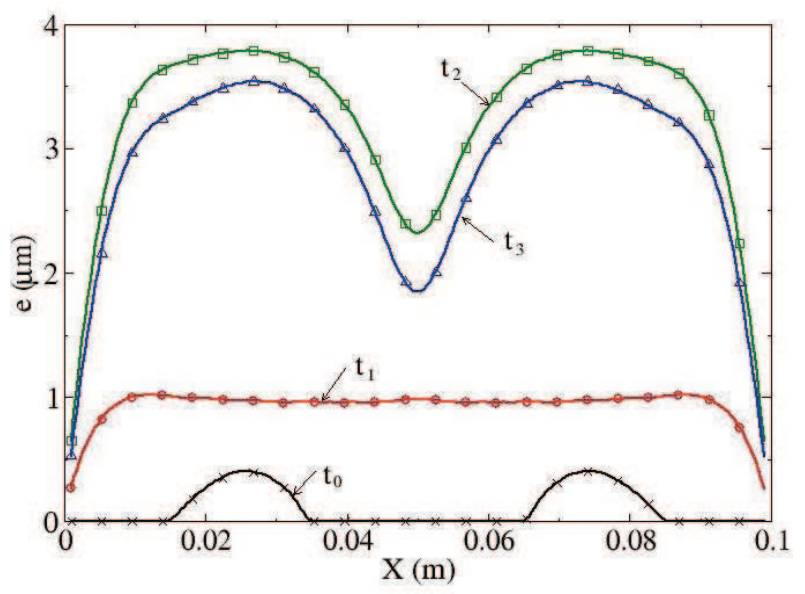

(a) Top wall.

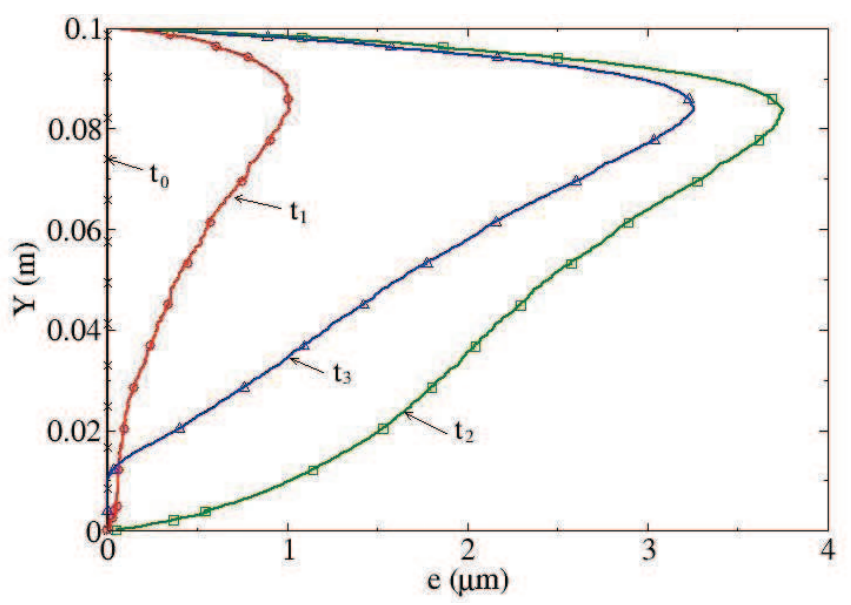

(b) Vertical walls.

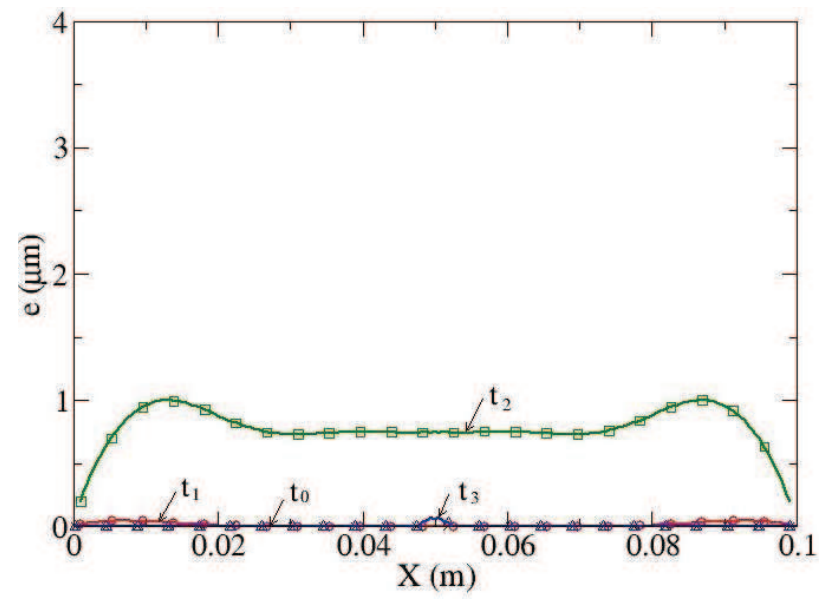

(c) Bottom wall.

Figure 12. Film thickness distributions along the walls at times $t_{0}$ to $t_{3}$ corresponding to the scalar fields shown in Fig. 13. 


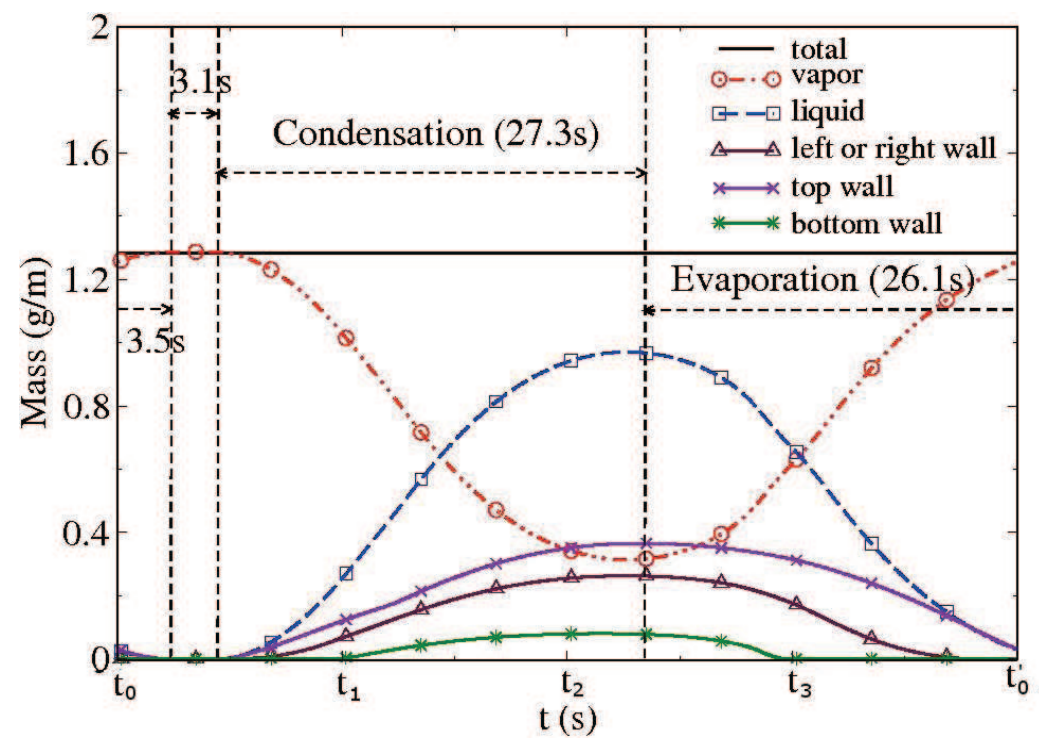

Figure 13. Time variations of the mass of liquid water at the walls and of the mixture mass in one time period. 


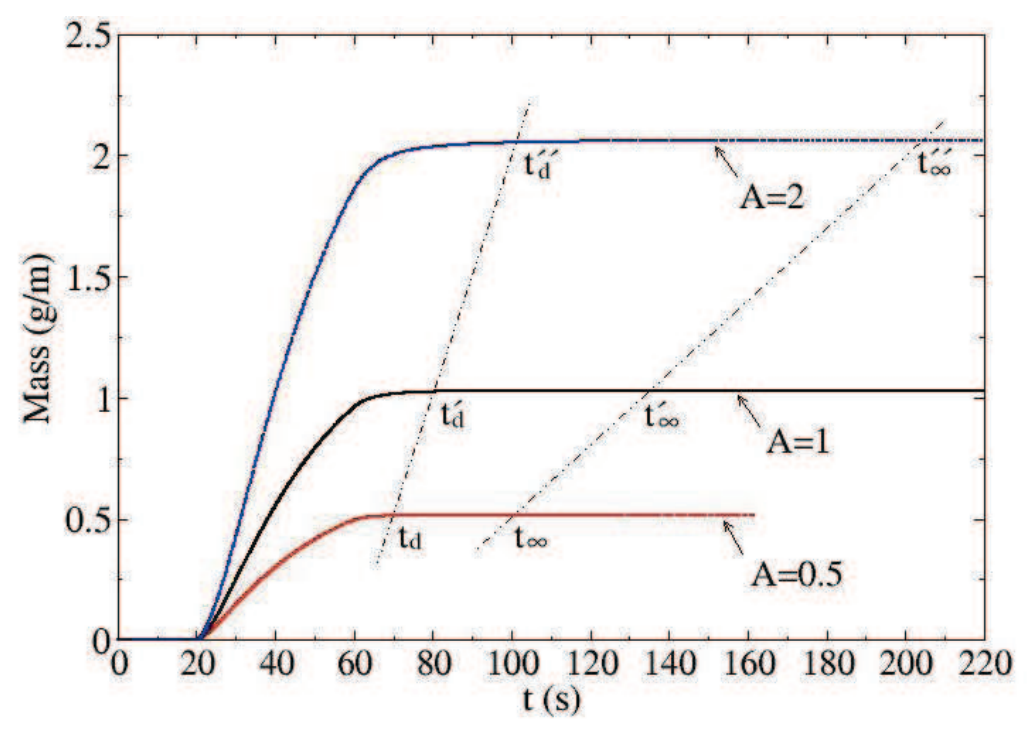

Figure 14: Time variations of the mass of liquid water condensed at the four walls according to the aspect ratio for constant width of the cavity $(\mathrm{L}=0.1 \mathrm{~m}) \cdot \mathrm{t}_{\mathrm{d}}$ and $\mathrm{t}_{\infty}$ indicate the beginning and the end of the diffusion period.

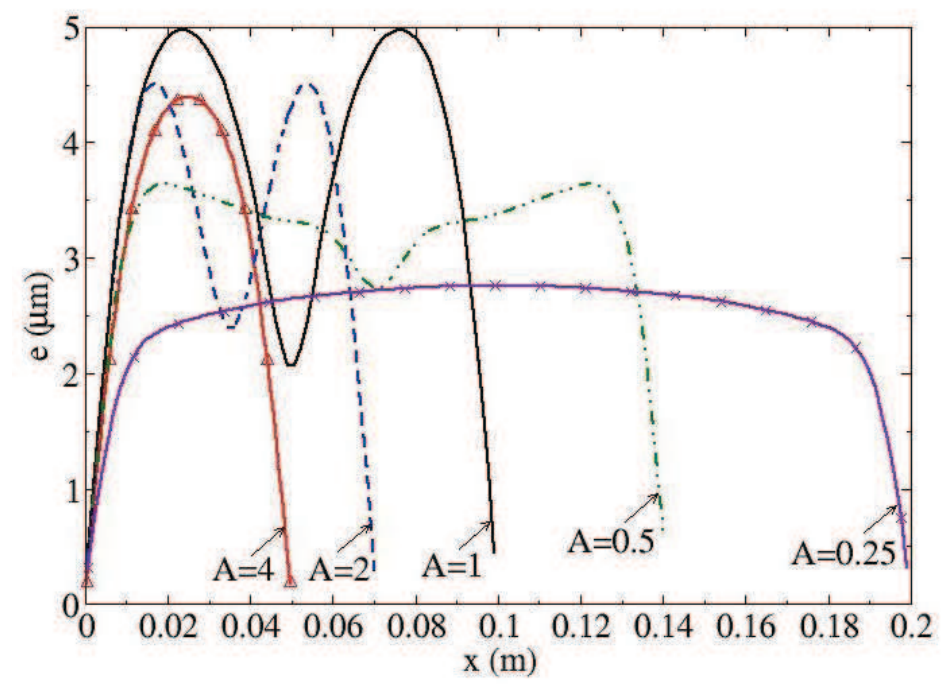

Figure 15: Steady-state thickness distribution of the liquid film at the top wall for five aspect ratios and constant volume of the cavity $\left(\Omega=10^{-2} \mathrm{~m}^{3} / \mathrm{m}\right)$ 